\title{
High Stability Au NPs: From Design to Application in Nanomedicine
}

\author{
Minwei Zhang (DiD ${ }^{1,2, *}$ \\ Shuxuan Shao ${ }^{1,2, *}$ \\ Haitao Yue ${ }^{1,2}$ \\ Xin Wang ${ }^{3}$ \\ Wenrui Zhang ${ }^{1,2}$ \\ Fei Chen ${ }^{1,2}$ \\ Li Zheng ${ }^{1,2}$ \\ Jun Xing ${ }^{1,2}$ \\ Yanan Qin ${ }^{1,2}$ \\ 'College of Life Science \& Technology, \\ Xinjiang University, Urumqi, 830046, \\ People's Republic of China; ${ }^{2}$ Xinjiang Key \\ Laboratory of Biological Resources and \\ Genetic Engineering, Urumqi, 830046, \\ People's Republic of China; ${ }^{3}$ The First \\ Hospital of Jilin University, Changchun, \\ |3006 I, People's Republic of China
}

*These authors contributed equally to this work

Correspondence: Yanan Qin

Email qingyalan12345@sina.com

\begin{abstract}
In recent years, Au-based nanomaterials are widely used in nanomedicine and biosensors due to their excellent physical and chemical properties. However, these applications require $\mathrm{Au}$ NPs to have excellent stability in different environments, such as extreme $\mathrm{pH}$, high temperature, high concentration ions, and various biomatrix. To meet the requirement of multiple applications, many synthetic substances and natural products are used to prepare highly stable Au NPs. Because of this, we aim at offering an update comprehensive summary of preparation high stability Au NPs. In addition, we discuss its application in nanomedicine. The contents of this review are based on a balanced combination of our studies and selected research studies done by worldwide academic groups. First, we address some critical methods for preparing highly stable Au NPs using polymers, including heterocyclic substances, polyethylene glycols, amines, and thiol, then pay attention to natural product progress Au NPs. Then, we sum up the stability of various Au NPs in different stored times, ions solution, $\mathrm{pH}$, temperature, and biomatrix. Finally, the application of Au NPs in nanomedicine, such as drug delivery, bioimaging, photothermal therapy (PTT), clinical diagnosis, nanozyme, and radiotherapy (RT), was addressed concentratedly.
\end{abstract}

Keywords: high stability Au NPs, polymer, natural product, resistance, nanomedicine

\section{Introduction}

As the most stable noble nanomaterials, Au NPs have been researched and applied for thousands of years. Compared with other nanomaterials, Au NPs exhibit many different properties. These unique physical properties of Au NPs are mainly attributed to the quantum size effect when the size of Au NPs decreases to a specific value (about 20nm), the magnetic, optical, acoustic, thermal, electrical, and superconducting properties of $\mathrm{Au}$ NPs are significantly different from those of conventional materials. ${ }^{1}$ Because of these unique physical properties and excellent biocompatibility, Au NPs have great potential in biomedical fields such as drug delivery, biological imaging, photothermal therapy, and clinical diagnosis. ${ }^{2}$ For example, it could be combined with DNA or proteins through electrostatic interactions. Because of their magnetic properties at the nanometer scale, Au NPs can achieve targeted delivery of biomolecules under the control of an external magnetic field. ${ }^{3,4}$ Likewise, the excellent biocompatibility, easy-to-control size, shape, and functionalization of Au NPs make them an ideal drug delivery vehicle. ${ }^{5}$ What's more, the large specific surface area of the Au NPs can cause the free electrons in them to resonate locally and exhibit a unique local surface plasmon resonance (LSPR) effect. ${ }^{6}$ Surface plasmons (SPs) refer to the electron density waves propagating along the metal surface (crosssection) generated by the interaction of freely vibrating electrons and photons on the 
metal surface. More importantly, it can be excited by electrons or light waves, enhancing peripheral fluorescence emission and producing light-to-heat conversion, thereby validly improving light absorption efficiency, making the $\mathrm{Au}$ NPs have photothermal conversion capabilities. ${ }^{7}$ At present, the application of photothermal therapy for $\mathrm{Au}$ NPs is concentrated in the near-infrared region (NIR). Moreover, two NIR (NIR-I 650-900nm, NIR-II 1000$1200 \mathrm{~nm}$ ) wavelength light has a strong penetrating ability in biological tissues, can obtain better light absorption and light-to-heat conversion efficiency in the NIR by adjusting the size and structure of $\mathrm{Au}$ NPs. ${ }^{8}$ Among them, the rodshaped Au NPs have the strongest light-to-heat conversion efficiency due to their excellent dispersibility and adjustable ratio. Many works have confirmed that its maximum heating efficiency can exceed $90 \%$ under near-infrared light irradiation. ${ }^{9}$ These factors make Au NPs considered as an ideal candidate for photothermal therapy. On the other hand, the surface plasmon effect of nanomaterials makes Au NPs have excellent fluorescence quenching ability and become a quencher in fluorescence resonance energy transfer (FRET) based biosensor materials. ${ }^{10}$ Furthermore, the easy-to-controllable size and functionalization of Au NPs can enable some fluorescent groups, quantum dots, antibodies to be modified on their surface to construct nanoprobes to achieve a rapid and accurate clinical diagnosis. ${ }^{11-15}$ However, $\mathrm{Au}$ NPs applied in nanomedicine require it should keep high stability in various conditions, like the concentration and type of salt ions, $\mathrm{pH}$, and biomolecules. ${ }^{16}$ Increasing the concentration of salt ions in the solution will reduce the electrostatic repulsive force on the surface of the nanoparticles, thus causing them to shift like an unstable state and finally leading to the aggregation of $\mathrm{Au}$ NPs. Köper et al found that the stability of $\mathrm{Au}$ NPs decreased significantly with the increasing concentration of $\mathrm{NaCl}$ solution. ${ }^{17}$ Liu et al found that some high-affinity halogen anions, such as $\mathrm{Br}^{-}$, promote aggregation of $\mathrm{Au}$ NPs to some extent. And the cations of elements with larger atomic numbers induce the aggregation of $\mathrm{Au}$ NPs compared to small ones, which is due to the reduction of nanoparticle surface potential. ${ }^{18}$ Besides, $\mathrm{pH}$ is another critical factor affecting the stability of Au NPs. Au NPs can maintain good stability in pH 5-9. ${ }^{19}$ And aggregation of Au NPs is induced by over acid or over basic conditions..$^{20,21}$ In physiological systems, some biomolecules can significantly affect the stability of $\mathrm{Au}$ NPs. Proteins in the biological matrix can change the stability of Au NPs through electrostatic adsorption. For example, bovine serum albumin (BSA) can adsorb on the surface of nanoparticles and decrease their stability in the biological system. Similarly, amino acids can alter the surface charge of Au NPs, causing aggregation. ${ }^{22-24}$ Larson et al reported that the interaction of cysteine with Au NPs also destabilized the Au NPs. ${ }^{25}$ Kimling et al found that excessive $\mathrm{Vc}$ adsorption on the surface of $\mathrm{Au}$ NPs causes aggregation. $^{26}$

Nowadays, except requiring the excellent stability of Au NPs during synthesis, the colloid's final stability must also be considered, which is very important for the storage and application of $\mathrm{Au}$ NPs, such as bioimaging and cancer therapy. ${ }^{19,20,27-29}$ For those issues, the primary method at this stage is to prepare or modify Au NPs to improve their stability through different materials or synthetic methods. Some polymers and natural products have recently been employed to synthesize different structures and particle size Au NPs. These Au NPs have been evaluated against harsh conditions such as extreme $\mathrm{pH}$, high concentration ions, various biomatrix, etc. The overall goal of this review is to provide a critical overview of our current understanding of $\mathrm{Au}$ NPs and their applications against various conditions. We will discuss how to prepare high stability $\mathrm{Au}$ NPs and then focus on Au NPs against longtime storage, extreme $\mathrm{pH}$, various biomatrix, etc. Finally, we introduce the latest research progress in biomedicine based on Au NPs. Figure 1 outlines the interest and focus of the present review.

\section{Preparation of High Stability Au NPs}

At present, Au NPs could be synthesized via chemical reduction methods, including the Turkevich method, Brust-Schiffrin method, and seed growth method. ${ }^{30-33}$ The Turkevich (or citrate) method is designed in a straightforward, single-phase, and simple route to obtain spherical $\mathrm{Au}$ NPs to use trisodium citrate as an Au salt reducing agent. ${ }^{34}$ Through this method, we can quickly and easily get $\mathrm{Au}$ NPs with controllable size. Turkevich method was usually synthesized spherical Au NPs, so it has limitations. ${ }^{35}$ Beyond that, the Brust-Schiffrin method is also a commonly used chemical synthesis method. ${ }^{36}$ As a two-phase synthesis and stabilization method, the preparation process is rapid and straightforward. It mainly stabilizes and modifies Au NPs through thiol functionalization and ligand exchange. Moreover, the seed-mediated method can synthesize Au NPs of different shapes but put forward higher requirements for various reaction factors. ${ }^{37}$ 


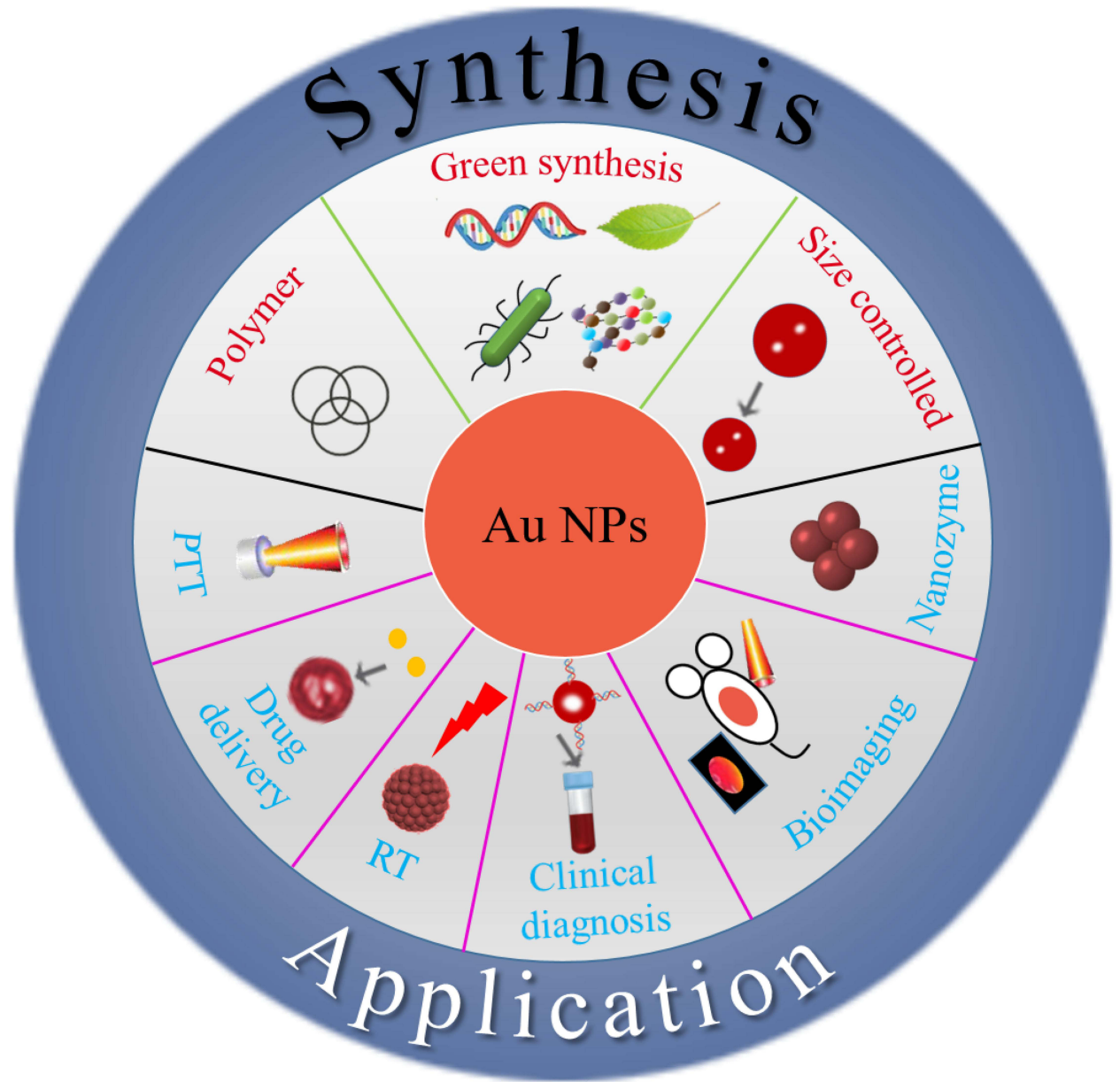

Figure I An overview of high stability Au NPs: From design to application in nanomedicine.

Therefore, we urgently need some strategies to prepare highly stable Au NPs with excellent biocompatibility that can be widely used in the biomedical field and have convincing examples, such as antibody binding. ${ }^{38}$ The subsequent modification of the surface chemistry of Au NPs can be accomplished through ligand exchange to adjust colloidal properties further, improve stability and expand applicability. For example, some polymers and biologically active substances are used as the capping agents or reducing agents to synthesis high stable Au NPs, particularly in natural product green synthesis Au NPs. This method has significant advantages compared with other methods, which are reliable, clean, and bio-friendly. ${ }^{39,40}$ Besides, due to the smaller size, the ultra-small Au NPs have better stability. ${ }^{41}$ To date, many natural products have been reported to successfully synthesize highly stable Au NPs, ranging from plants, bacteria to fungi. Herein, for chemical methods, we mainly introduce some recent advances in the preparation of Au NPs from polymers and organics; for biosynthesis methods, we mainly introduce the aspects of plants, microbes, proteins, genetic materials (DNA, RNA). Finally, we discuss the preparation of ultra-small Au NPs with controllable size. The various synthesis methods are summarized in Figure 2.

\section{Polymer Functionalized Au NPs}

Nowadays, polymers as protective groups to synthesize high stability Au NPs have been attracted more and more attention. There are three main approaches for preparing Au NPs from polymers: direct synthesis, "grafting from," and "grafting to" strategy. ${ }^{42}$ The direct method is to obtain Au NPs by reducing tetrachloroauric acid with a reducing agent under the protection of the thiol group, such as poly (N-isopropyl acrylamide) (PNIPAM) and polystyrene (PS) ${ }^{43-46}$ "Grafting from" technology refers to attaching polymer functional groups to the surface of Au NPs through ligand exchange, usually in the presence of chain transfer agents or initiators. For example, 


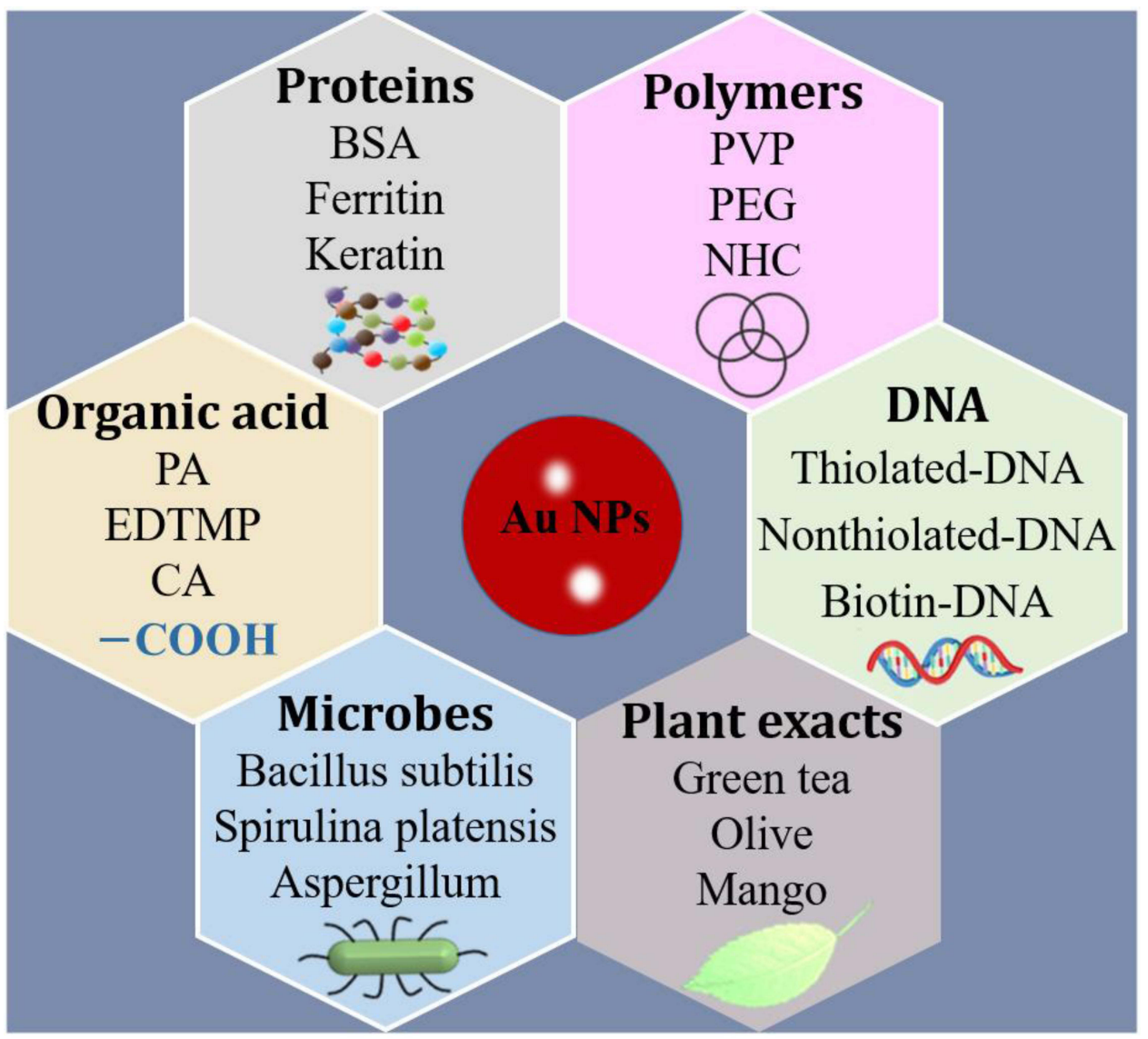

Figure 2 Various methods of synthesis high stable Au NPs.

PNIPAM and polyacrylic acid (PAA) can be used to graft from the surface of Au NPs for functionalization. ${ }^{4-50}$ Another approach is the "grafting to" strategy, which is to graft polymer containing sulfhydryl, amino, and other functional groups on the surface of Au NPs by way of ligand substitution to obtain composite $\mathrm{Au}$ NPs. ${ }^{51,52}$ Many studies have confirmed that the "grafting to" method can get Au NPs with high stability. For example, poly (2-(dimethylamino)ethyl methacrylate (PDMA) and poly (2-(methacryloyloxy)ethylphosphocholine) (PMPC) can synthesize excellent stability of $\mathrm{Au} \mathrm{NPs}{ }^{53}$ More importantly, by this method, the assembled structure of $\mathrm{Au}$ NPs can be well controlled to meet the specific application's needs via adjusting structural parameters (such as ratio and molecular weight) of the hydrophilic and hydrophobic partitions of the amphiphilic polymer.

What is more, using some polymer as capping agent can improve the stability and light-to-heat conversion efficiency of nanoparticles. ${ }^{54,55}$ These polymer-encapsulated Au NPs maintained the self-assembly behavior of the amphiphilic polymers, resulting in a series of functional nanostructures. ${ }^{56}$
Polymer capping agents can further improve the stability of Au NPs. Therefore, many scholars have adopted polymers to synthesize Au NPs based on the Turkevich method, especially some responsive polymers that can give Au NPs some new properties to respond to external stimuli. In this way, the colloidal properties may vary with $\mathrm{pH}$, ionic strength, redox potential, temperature, etc. ${ }^{57-62}$ In addition, these responsive polymers can also enhance the stability of Au NPs and expand their application range. In general, the polymers used to synthesize Au NPs are currently classified according to their functional groups and mainly divided into heterocyclics, alcohols, and amines. ${ }^{63-65}$

\section{Heterocyclic Substances}

Some heterocyclic substances can reduce the Au precursors to prepare stable water-soluble and uniformly tunable Au NPs. Keeping nanoparticles' long-term and reasonable stability in biological relevant ionic media. ${ }^{66}$ This is maybe due to $\mathrm{N}$ heterocyclic molecules (NHC) can form stronger bonds with metals. ${ }^{67}$ The primary mechanism for carbon-based heterocyclic synthesis of Au NPs is the use of long alkyl chains to exchange ligands on nanoparticles 
Top-down approach (TD)
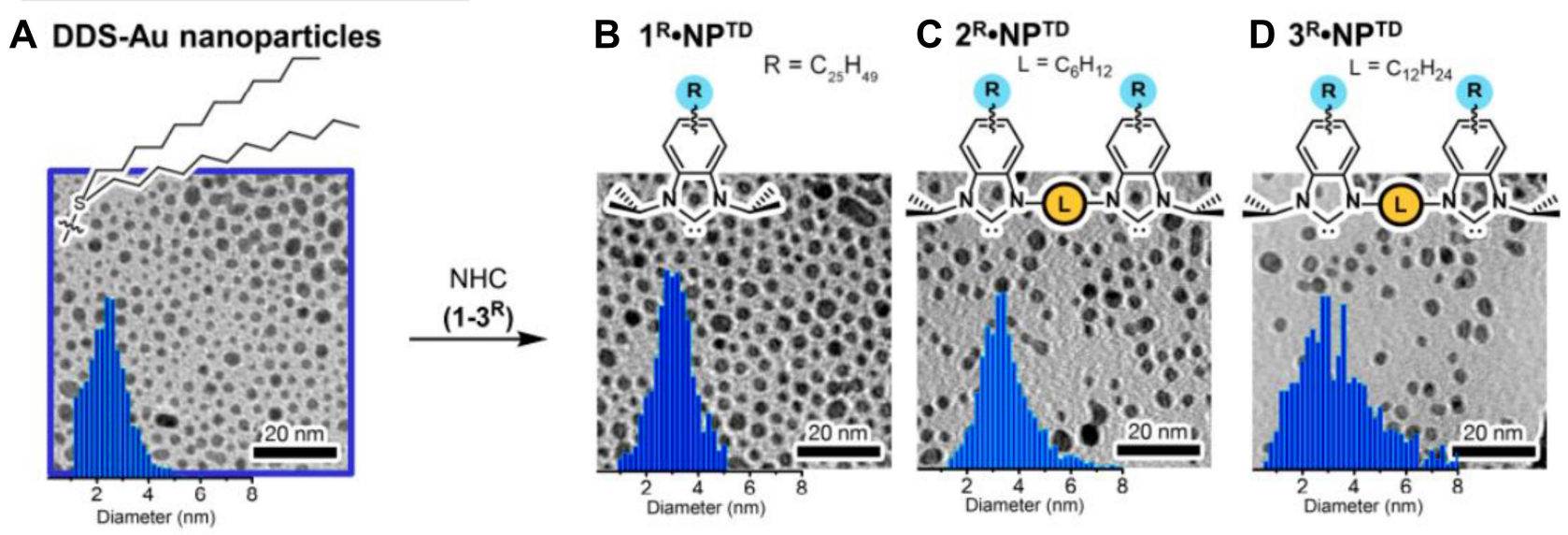

\section{Bottom-up approach (BU)}
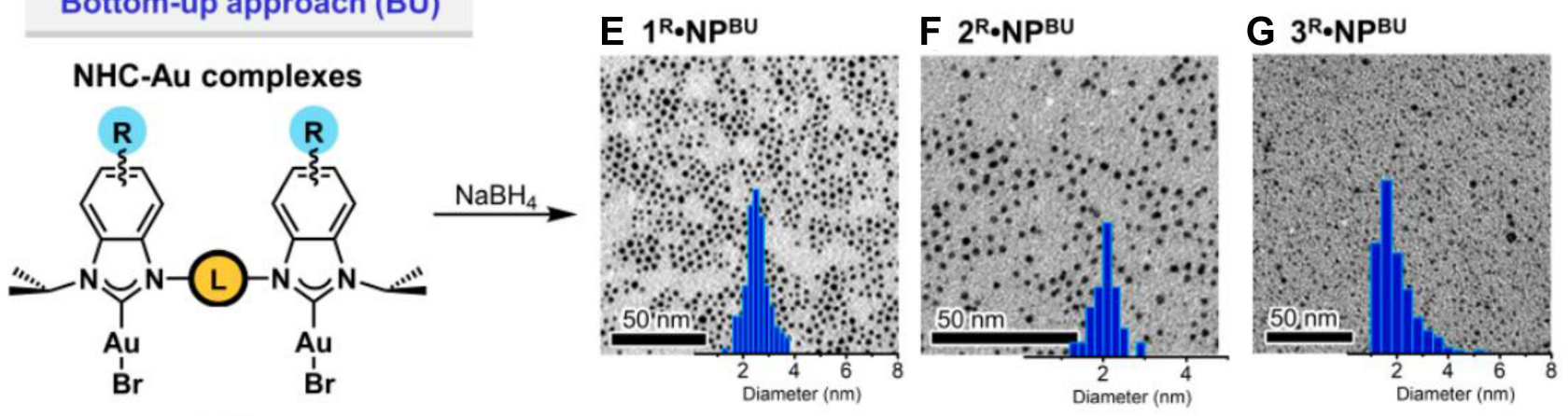

$1-3^{R}$

Figure 3 TEM images and particle size distributions of Au NPs stabilized by DDS, and free carbenes $\left(I-3^{R}\right)$ stabilized Au NPs prepared by the top-down and bottom-up approaches. (A) DDS-Au NP, (B) $I^{R} \cdot A u N P^{T D}$, (C) $2^{R} \cdot A u N P^{T D}$, (D) $3^{R} \cdot A u N P^{T D}$, (E) $I^{R} \cdot A u N P^{B U}$, (F) $2^{R} \cdot A u N P^{B U}$, (G) $3^{R} \cdot A u ~ N P^{B U}$. Reprinted with permission from Man RWY, Li CH, MacLean MWA, et al. Ultrastable gold nanoparticles modified by bidentate N-heterocyclic carbene ligands. J Am Chem Soc. 2018;140:1576-1579. Copyright (2018) American Chemical Society. ${ }^{63}$

self-assembly. ${ }^{68,69}$ Compared with the Au-S bond, the covalent bond formed by the NHC and Au NPs is stronger, which makes the nanoparticles have better stability in different physiological environments. ${ }^{70-73}$ Many reports have confirmed that NHC-stabilized Au NPs have great potential in biomedicine. ${ }^{69,73}$ As a common NHC, under the action of an initiator, polypyrrole (PPy) is used as a protective agent to synthesize a composite urchin-like $\mathrm{Au} \mathrm{NP}$ of about $6 \mathrm{~nm}$ utilizing oxidative polymerization. Compared with bare Au NPs, PPy-coated Au NPs have excellent stability under long-term storage, heat, $\mathrm{pH}$, and laser irradiation and improve light-to-heat conversion efficiency. ${ }^{74}$ The latest research shows that bidentate NHC is a new end-capping ligand to synthesize Au NPs by top-down and bottom-up approaches. For the top-down method, dodecyl sulfide-protected nanoparticles follow the Brust-Schiffrin method. For the bottom-up preparation, mono-and bidentate $\mathrm{NHC}-\mathrm{Au}$ complexes were reduced with $\mathrm{NaBH}_{4}$ in ethanol affording the corresponding $\mathrm{Au}$ NPs (Figure 3). The Au NPs obtained by both top-down and bottom-up maintained better stability after heating at $130{ }^{\circ} \mathrm{C}$ for 24 hours due to the larger ligand density (Figure 4). ${ }^{63}$

\section{PEG-Based Polymer}

In recent years, the use of polyethylene glycol (PEG) to synthesize Au NPs has received more and more attention. As a typical alcohol polymer, PEG is widely used due to its low toxicity, good biocompatibility, and easy modification to the surface of Au NPs. ${ }^{75}$ Due to the very high specific binding affinity of gold to thiol groups, the groups in PEG can be direct covalently modified on the surface of $\mathrm{Au}$ NPs and bind firmly to it, making the system have electrostatic repulsion and provide a particular steric 

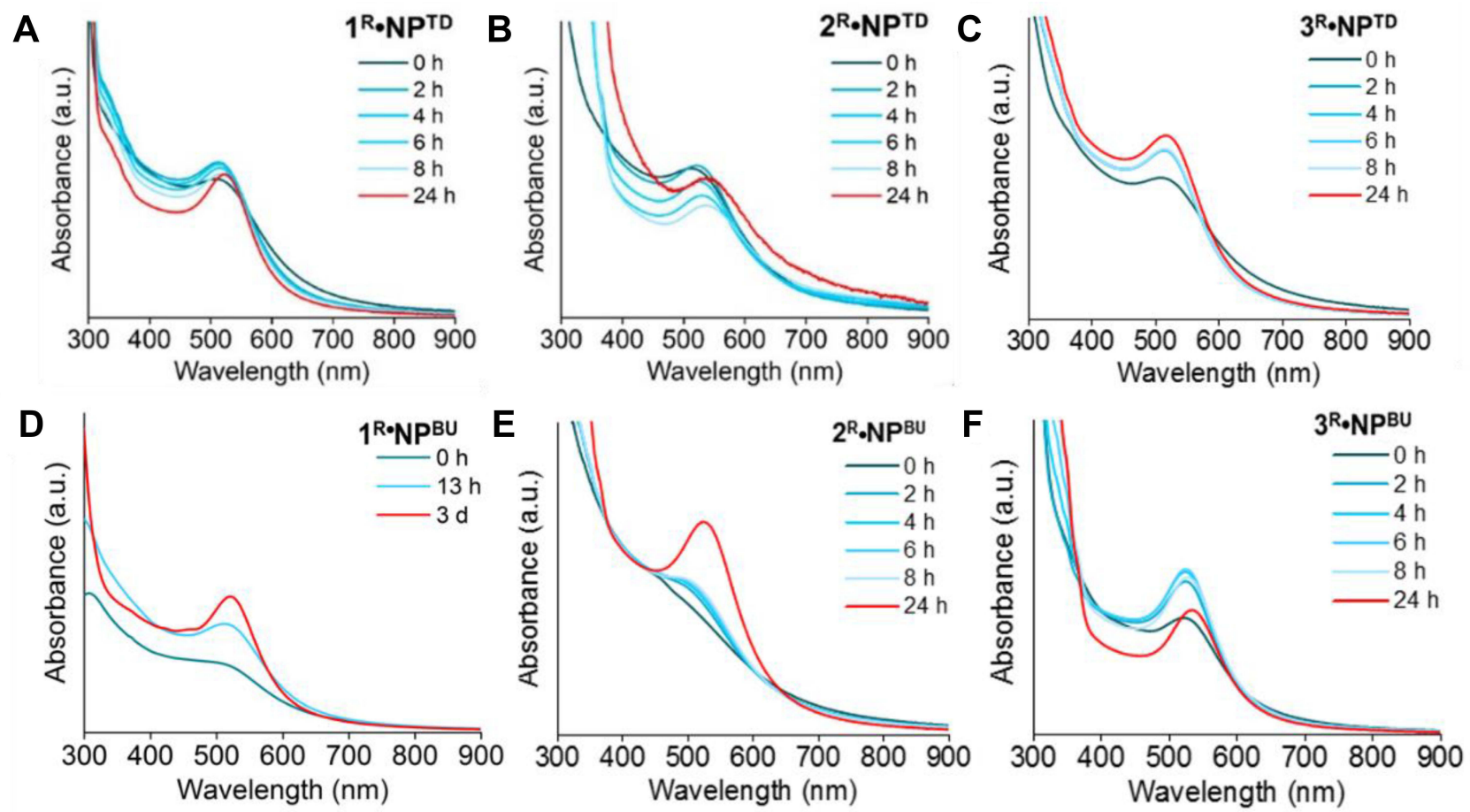

Figure 4 Stability studies of NHC-Au NPs. UV-vis spectra of NHC-Au NPs prepared from top-down and bottom-up approach, heated at I30 ${ }^{\circ} \mathrm{C}$ in xylenes. (A) $\mathrm{I}^{\mathrm{R}} \cdot \mathrm{Au}$ $N P^{T D}$, (B) $2^{R} \cdot A u N P^{T D}$, (C) $3^{R} \cdot A u N P^{T D}$, (D) $1^{R} \cdot A u N P^{B U}$, (E) $2^{R} \cdot A u N P^{B U}$, (F) $3^{R} \cdot A u N P^{B U}$. Reprinted with permission from Man RWY, Li CH, MacLean MWA, et al. Ultrastable gold nanoparticles modified by bidentate N-heterocyclic carbene ligands. J Am Chem Soc. 2018;140:1576-I579. Copyright (2018) American Chemical Society. ${ }^{63}$

hindrance to prevent salt and biomolecules induced aggregation. $^{76,77}$ For example, in the serum-containing phosphate buffer, PEG forms a dense layer on the surface of $\mathrm{Au}$ NPs, prevents the adhesion of BSA, and can significantly improve the stability of $\mathrm{Au}$ NPs. ${ }^{78}$ Besides, $\mathrm{Au}$ NPs can be modified by ligand exchange with different anchor groups of PEG, such as monothiol (MP7M), flexible dithiol (BP7M), constrained dithiol (DP7M), and disulfide bond (TP7M), all of which are improved the stability of $\mathrm{Au}$ NPs to a certain extent. The disulfide bond modified $\mathrm{Au}$ NPs have the best stability and can maintain specific stability for 15 minutes at $100^{\circ} \mathrm{C}$ in a 2 $\mathrm{M} \mathrm{NaCl}$ solution. Because the disulfide bond groups attached to the surface of the Au NPs form a dense structure. $^{79}$ Next, Park et al facilely synthesized PEGcoated $\mathrm{Au}$ NPs by reducing the gold precursor. Due to the chelating effect of the group, Au NPs can keep several months of stability under the cell physiological environment simulated by the mixed solution of 3.0 M DTT and $2.0 \mathrm{M} \mathrm{NaCl}^{80}$ In addition to physiological environments, some Au NPs modified with PEG can maintain long-term stability at high temperatures. Since Au NPs are often used in the photothermal treatment of tumors, their thermal stability is also the main direction of current research. The latest study shows that the physical sputtering method can synthesize Au NPs covered with PEG with uniform size and shape, ultra thermal stability $\left(100{ }^{\circ} \mathrm{C}\right)$ without cytotoxicity. ${ }^{81}$ Except for PEG, some surfactants can also improve the stability of $\mathrm{Au}$ NPs. ${ }^{82}$ In particular, it can slow down the deformation caused by the maturation of Au nanomaterials, thereby improving its thermal stability. For example, Au nanofluids were synthesized using Gemini surfactant butane 1,4 (N-tetradecyl-N, $\mathrm{N}$-dimethyl); ammonium bromide has better thermal stability. The results of UV-Vis spectroscopy showed that it was at $150{ }^{\circ} \mathrm{C}, 140{ }^{\circ} \mathrm{C}$ and $130{ }^{\circ} \mathrm{C}$ stables for 8 hours, 12 hours and 20 hours, respectively. ${ }^{83}$

\section{Amine-Terminated Polymers}

The organic compound amine is also commonly used as a protecting group to synthesis Au NPs. Since the amine molecule can cap the Au NPs in the solution and the nanoparticles are stabilized covalently, the colloid has good dispersibility. For example, 2-methyl aniline (MA) protects $\mathrm{Au}$ NPs with an average diameter of $20 \mathrm{~nm}$. Due to the oxidative polymerization of amine to form 
a polymer shell on the surface of Au NPs, it has excellent stability. ${ }^{65}$ Rajesh Sadar et al used polyallylamine (PAAM) to synthesize PAAM-Au NPs. Then they tested the prepared small-sized Au NPs $(<3 \mathrm{~nm})$ in solutions of different $\mathrm{pH}$ and found that it can still maintain better stability under the conditions of $\mathrm{pH} 1.5$ and 3.5. More interestingly, $\mathrm{Au}$ NPs can be assembled into various structures at different $\mathrm{pH}$ values, which significantly expands its scope of application. ${ }^{84}$ Nowadays, the latest report shows that polypropylene imine (PPI) can be used to synthesize highly stable dendritic Au NPs. The high density of functional groups on the surface of nanoparticles significantly improves their stability under different physiological conditions (phosphate buffer solution, serum, Hanks buffer). ${ }^{85}$ Susumu et al used maleimide as a ligand to terminate $\mathrm{Au}$ NPs, which can be stable for 10 days under $2 \mathrm{M} \mathrm{NaCl}$ and 0.5-1 M DTT conditions. ${ }^{86}$ As an amide polymer, polyvinyl pyrrolidone(PVP) can stabilize and prevents the aggregation of $\mathrm{Au}$ NPs. It can well control the morphology of the nanoparticles. What's surprising, a minimal amount of PVP can achieve excellent stabilization effects on $\mathrm{Au}$ NPs. ${ }^{87}$ Besides, some amine salts, such as polyallylamine hydrochloride (PAH) can also be used to prepare Au NPs $(5-50 \mathrm{~nm})$ with controllable size by in-situ growth. The synthesis method is simple, and the prepared Au NPs have good stability and biocompatibility. ${ }^{88}$ Also, dendritic polyamide amide (PAMAM) can be used as a template for modification to obtain highly stable Au NPs. Next, they confirmed that the particular zwitterionic layer on the surface of the modified Au NPs limits the interaction between fibrinogen and Au NPs, so it has higher stability in the fibrinogen solution (within 24 hours). ${ }^{89}$

\section{Thiol Terminated Polymers}

$\mathrm{Au}$ NPs can be conjugated with a variety of groups by simple chemical methods, such as sulfhydryl groups. ${ }^{47,90}$ Thiol is a class of compounds containing sulfhydryl functional groups, usually cross-linked with Au NPs using Au-S bonds to protect and stabilize the nanoparticles. For example, previous research shows that the ligand exchange synthesis between Au citrate and dithiol is very stable and can resist the external environment, which may be due to the tight binding of the dithiol group of dihydrolipoic acid (DHLA) to the surface of Au NPs. ${ }^{91}$ Besides, Li et al prepared aliphatic thiol-stabilized Au NPs. They confirmed that it can still maintain better stability even in $0.1 \mathrm{M}$ dithiothreitol solution. ${ }^{92}$ Next, based on the Brust method, Kornberg et al take advantage of ligand exchange reaction prepared
$\mathrm{Au}$ NPs, the nanoparticles with controllable size by adjusting the ratio of thiol and $\mathrm{HAuCl}_{4}$. Perhaps surprisingly, the $\mathrm{Au}$ NPs produced by this strategy can be stable in an aqueous solution for several years under thiol protection. ${ }^{93}$

\section{Acid-Induced Synthesis High Stability Au NPs}

As a general compound, acid can induce synthesis Au NPs, and it exhibits excellent stability under specific physiological environments. In detail, acid-functionalized can modify Au NPs and broaden their application range while improving their stability. Phosphonic acid (PA) is one of them. Due to the excellent hydrophilicity of the PA groups on the surface of Au NPs and the electrostatic repulsion and steric hindrance between them to protect the Au NPs. For example, ethylenediamine-tetramethylene phosphonic acid (EDTMP) can be used to synthesize phosphonic acid-functionalized $\mathrm{Au}$ NPs. Zhang et al synthesized phosphonic acid-functionalized $\mathrm{Au}$ NPs. The characteristic peaks of $\mathrm{P}=\mathrm{O}, \mathrm{PO}_{3}$, and $\mathrm{P}-\mathrm{OH}$ were found by Fourier transform infrared spectroscopy (FTIR), which further confirmed that the phosphonic acid groups were successfully modified on the surface of the Au NPs. They found that under $25 \mathrm{mM}$ PBS buffer ( $\mathrm{pH}$ 7.0), Au NPs were almost the same as the initial absorbance, and further research shows that the absorbance of $\mathrm{Au}$ NPs remained virtually constant in the $\mathrm{pH}$ range of 3.0-12.0. Meanwhile, after 3 months of storage, no flocculation or aggregation of Au NPs was observed. ${ }^{94}$ Except phosphonic acid, some other acids are also used to synthesize highly stable $\mathrm{Au}$ NPs. For example, Mohammad et al synthesized Au NPs coated with PEGylated deoxycholic acid (DCA). It exhibits excellent stability and can remain stable in a wide temperature range $\left(-78{ }^{\circ} \mathrm{C}-48{ }^{\circ} \mathrm{C}\right)$ and wide $\mathrm{pH}$ (2.5-11). More surprisingly, due to the higher $\mathrm{X}$-ray attenuation coefficient of Au NPs and the sensitivity of deoxycholic acid-specific tumor cells, PEGylated DCA@Au NPs are expected to be used in targeted tumor therapy and contrast agents. ${ }^{95}$ Besides, cinnamic acid (CA) can be used as a template to induce the self-assembly of $\mathrm{Au}$ NPs, and it can significantly improve the stability of nanoparticles. Then they further verified the stability of $\mathrm{Au}$ NPs; compared with the conventional chemical method, the Au NPs (5 nm) synthesized by this method can still maintain excellent stability when stored at room temperature for 3 months. ${ }^{96}$ 


\section{Green Synthesis}

The green synthesis of Au NPs is a hot spot in current research. It consists of two main categories: biological synthesis and biomimetic synthesis. Biological synthesis mainly uses extracts from some plants and microbes (including bacteria and fungi) as stabilizers or reducing agents to synthesize gold nanomaterials. ${ }^{97,98}$ Biomimetic synthesis refers to biomolecules and water as reaction reagents to guide the synthesis of nanomaterials under defined reaction conditions with the metabolites of living organisms as substrates. ${ }^{99-101}$ Biomimetic synthesis overcomes some apparent drawbacks of biosynthesis, such as low yield, difficulty to control the size and shape, and further separation and purification of the obtained polydisperse gold nanomaterials. It's a new synthesis strategy evolved from biological synthesis. ${ }^{102,103}$

\section{Plant Extract-Mediated Synthesis}

Nowadays, Au NPs synthesized from plant-based phytochemicals are extremely attractive for their unique efficacy and biocompatibility. ${ }^{40}$ Meanwhile, the plant-mediated method is synthesized at room temperature and does not require additional chemical reagents. The prepared $\mathrm{Au}$ NPs have unique properties, such as antioxidant, antitumor activity, and antibacterial activity. ${ }^{104-106}$ At present, the major drawback of stabilizing Au NPs by plant extracts is that it is difficult to control the shape and size of the nanoparticles due to their anisotropic.

In terms of plant component-mediated synthesis, Jaewook Lee et al used some active ingredients extracted from plants, including Gallic acid (GA), protocatechuic acid (PCA), and isoflavones (IF) act as reducing agents to synthesize functionalized Au NPs with extremely high biocompatibility and stability, it can be stable for three months. Because the hydroxyl groups in the phytochemical composition have a high surface charge: the strong repulsion between them can prevent Au NPs from agglomerating. ${ }^{107}$ Besides, the preparation of biogenic Au NPs from plants with high medicinal value such as Plumbago zeylanica, Dioscorea bulbifera, Gloriosa superba, and Gnidia glauca has also received much attention. Similarly, it relies on the hydroxyl groups of compounds (such as alkaloids, reducing sugars, phenols, tannins, saponins, and flavonoids) to bioreduce $\mathrm{Au}^{3+}$ ions to $\mathrm{Au}$, and the carbohydrates of plant extract may be used to stabilize Au NPs ${ }^{108-112}$ In general, $\mathrm{HAuCl}_{4}$ binds to plant extracts through carbon-chlorine bonds. ${ }^{113}$ In addition, during the synthesis process, some of the gold seeds elongated without forming gold nuclei due to incomplete reaction, resulting in some irregular aggregation of nanoparticles and obtaining anisotropic Au NPs. Moreover, glucose and starch can also reduce agents and stabilizers to synthesize Au NPs in different buffers. Subsequently, experiments confirmed that Au NPs synthesized in MES buffer have long-term stability and can be stored at room temperature for 17 months. ${ }^{114}$ Similarly, glycerin extracted from natural oils and fats can also be used as a material to synthesize Au NPs. Rashida Parveen et al used glycerin as a reducing agent and stabilizer to synthesize uniform-sized Au NPs with excellent biocompatibility and stability. And the size of Au NPs can be controlled by the ratio of glycerin to the water. ${ }^{115}$ Due to the catalytic ability of glycerol and the superior safety of obtaining Au NPs, this synthetic method is expected to be used in the fields of catalysis and biomedicine. Using the extract of the olive leaf as a reducing agent can prepare Au NPs with better stability and non-toxicity. This method is easy to synthesize and has a higher reaction rate. ${ }^{116,117}$ Besides, mango leaves can also be used to synthesize Au NPs. The extract of mango leaves contains various active ingredients such as phenolic acids, terpenes, and glycosides. ${ }^{118}$ At present, studies have shown that using some mango leaf extracts can rapidly synthesize spherical Au NPs without heating, and obtained nanoparticles have ultrahigh colloidal stability. It can be stable for more than 5 months at room temperature, which may be due to the active ingredients in the mango leaves. ${ }^{119}$ And the tannin in bayberry can also be used to obtain $\mathrm{Au}$ NPs with excellent biocompatibility effectively. Among them, bayberry tannin serves as a reducing agent as well as a stabilizing agent. At the same time, the size of the nanoparticles can be adjusted by the concentration of tannin. This green synthesis method does not require other toxic chemical reagents and has comparatively higher practical value. ${ }^{120}$ And as a natural ingredient in plants, Gum Arabic (GA) can be used as a stabilizer and a reducing agent to synthesize Au NPs with steric stability. Studies have confirmed that spherical $\mathrm{Au}$ NPs synthesized using GA and $\mathrm{NaBH}_{4}$ have good stability under long-term storage conditions and can maintain physical stability for up to 5 weeks. ${ }^{121}$ Nowadays, glycans have received extensive attention due to their smaller molecular weight and advantages of binding to specific receptors. The functionalized Au NPs with some different glycans by ligand exchange have excellent biocompatibility and maintain high stability in serum proteins. ${ }^{122}$ This provides a new option for the synthesis of ultrastable and biocompatible Au NPs. 


\section{Microbes-Mediated Biosynthesis}

Except for natural ingredients in plants, nowadays, with the deepening of research, people have found that many microbes can also synthesize Au NPs. These microbes mainly include fungi and bacteria. Fungi can secrete proteins, which helps to regulate the morphology of Au NPs. At the same time, some bacteria can act as the reducing agents to synthesize and stabilize Au NPs. ${ }^{123,124}$ Microbes can easily and quickly stabilize Au NPs with low cost and environmental friendliness. ${ }^{125}$ Some microbes secrete proteins that can further protect Au NPs and improve their stability in complex physiological environments. ${ }^{126,127}$ What's more, this microbe-mediated synthesis of highly stable $\mathrm{Au}$ NPs is expected to have a wide range of applications in many fields. Many studies on the synthesis of Au NPs by fungi and bacteria have been reported based on this. For example, Aspergillus (WL-Au) can green synthesize Au NPs with controllable size under different reaction conditions (Figure 5). The prepared Au NPs have great catalytic activity and can be used for the depolarization of dyes. ${ }^{128}$ And as a common fungus, mushroom extracts can also synthesize $\mathrm{Au}$ NPs. Even more surprising is that the protein in the mushroom extract can stabilize Au NPs and prevents their aggregation. ${ }^{129}$ Equally, bacterial green synthesis of Au NPs also is a research hotspot in recent years. For instance, $\mathrm{Au}$ NPs can be prepared by Bacillus subtilis reduction. By this method, we can obtain Au NPs with robust antibacterial activity, which is expected to be used in the biomedicine and food industry. ${ }^{130}$ Beyond that, some algae in the ocean, such as Spirulina platensis, can be used as raw materials to synthesize Au NPs quickly. Due to many bioactive substances in Spirulina platensis, the prepared Au NPs have broad application prospects in the medical field. ${ }^{131}$

\section{Low Molecular Weight Protein Decorated Au NPs}

Biomolecules have become one of the best candidates for stabilizing Au NPs by their multifunctional chemical groups, high binding ability with metal molecules, and excellent biocompatibility. ${ }^{132,133}$ Due to their superb stabilizing ability, Au NPs can remain stable under various physiological environments. ${ }^{132,134}$ Moreover, while stabilizing $\mathrm{Au} \mathrm{NPs,} \mathrm{it} \mathrm{can} \mathrm{also} \mathrm{be} \mathrm{conjugated} \mathrm{with} \mathrm{different}$ specificities molecules to meet its application in biomedicine. ${ }^{135,136}$ Protein is one of them. More detailedly, not only Au NPs are immobilized by biomolecules because the functional groups in amino acids directly bind to nanoparticles through $\mathrm{Au}-\mathrm{S}$ covalent bonds, but also the protein-decorated Au NPs can significantly improve their dispersion and anti-aggregation stability in the biological matrix to meet applications in biosensor, diagnostic and therapeutic. $^{137,138}$

Based on this, at present, studies have shown that Au NPs synthesized with some proteins or amino acids exhibit excellent stability. For example, choline tryptophan and tetraethylammonium (TEA) can be used to prepare Au NPs, where the tryptophan group acts as a reducing agent. The nanoparticles synthesized by this method show superior stability in a specific concentration of hemoglobin buffer $(100-200 \mu \mathrm{L} / \mathrm{mL}) .{ }^{139}$ As a protein in the human body, ferritin has extreme safety and the ability to react with multiple substances. It can be wrapped on the surface of Au NPs for modification to enhance its stability, and other targeting molecules can be modified on nanoparticles for tumor treatment. Studies have shown that the Au NPs assembled by ferritin still have excellent thermal stability at $62.5^{\circ} \mathrm{C}$ and do not aggregate in $800 \mathrm{mM} \mathrm{NaCl}$ solution. ${ }^{140}$ With the deepening of research, people have discovered using specific proteins in the human body to decorated Au NPs can improve their long-term stability and avoid immune rejection. ${ }^{141}$ This discovery is expected to be a drug delivery system that uses Au NPs as a carrier. On the other hand, some protein-decorated Au NPs exhibit characteristics that are not available in conventional synthetic Au NPs. For instance, amino acids and peptides are added to the solution of $\mathrm{Au}$ NPs and grown in situ to obtain chiral Au NPs. More surprisingly, its unique optical activity contributes to the application in nanomedicine. ${ }^{142}$

In addition to the proteins contained in the human body, the proteins extracted from some fungi can also significantly enhance the biocompatibility and stability of Au NPs. For example, Au NPs prepared using protein from Rhizopus oryzae cells as a blocking agent have almost the same absorption wavelength in physiological buffer solution with a $\mathrm{pH}$ range of 6.5-7.5. Its good biocompatibility has been confirmed in the hemolysis test. ${ }^{143}$

\section{Designed and Controlled Genetic Material for the Synthesis of Au NPs}

At present, genetic materials (such as deoxyribonucleic and ribonucleic acid) are often used as templates to synthesize or modify Au NPs due to their unique selfassembly properties. ${ }^{144}$ These nucleotide-modified $\mathrm{Au}$ NPs show excellent biocompatibility. ${ }^{145}$ More importantly, it can protect the Au NPs by forming a dense layer on the surface of the Au NPs through the chemical bond, thereby further improving its stability. ${ }^{146}$ The currently commonly used synthesis strategy is to conjugate DNA to Au NPs via 
A

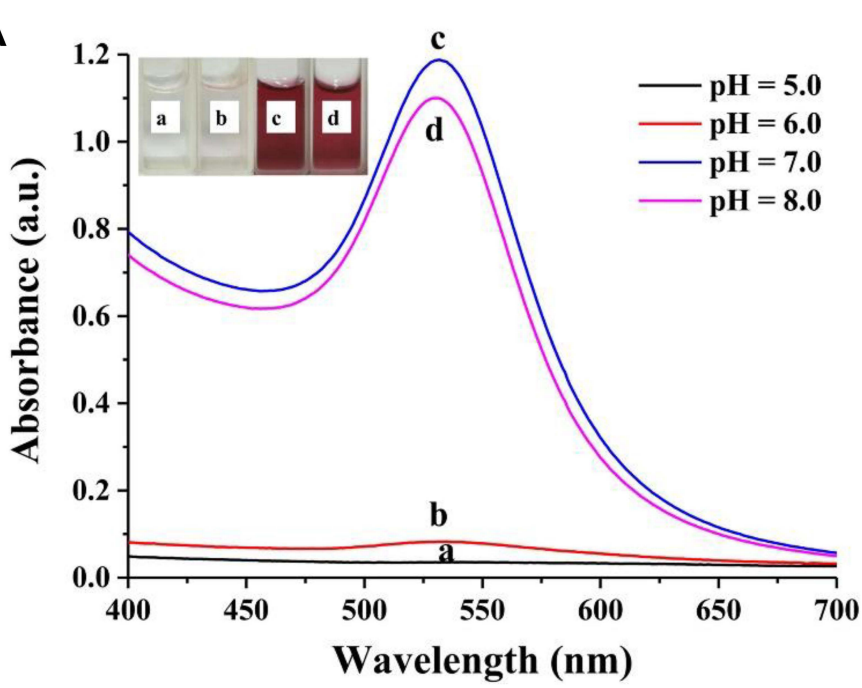

C

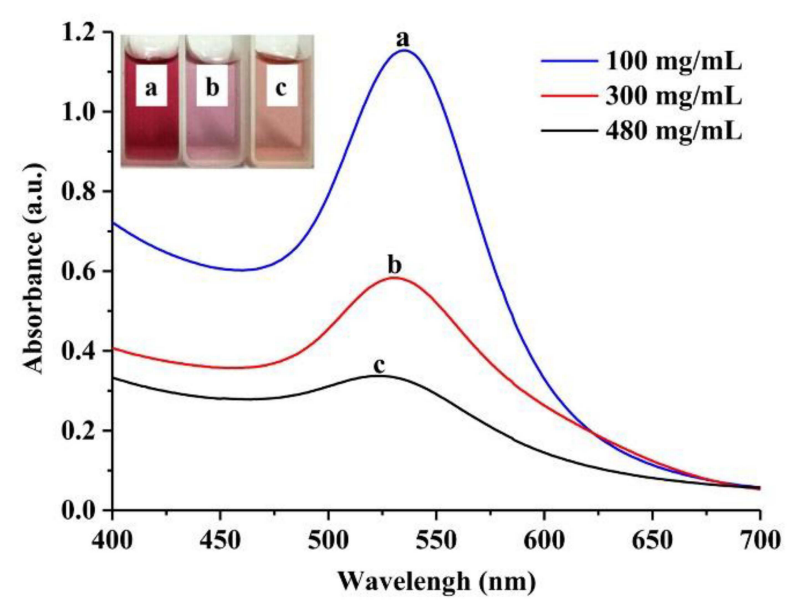

E

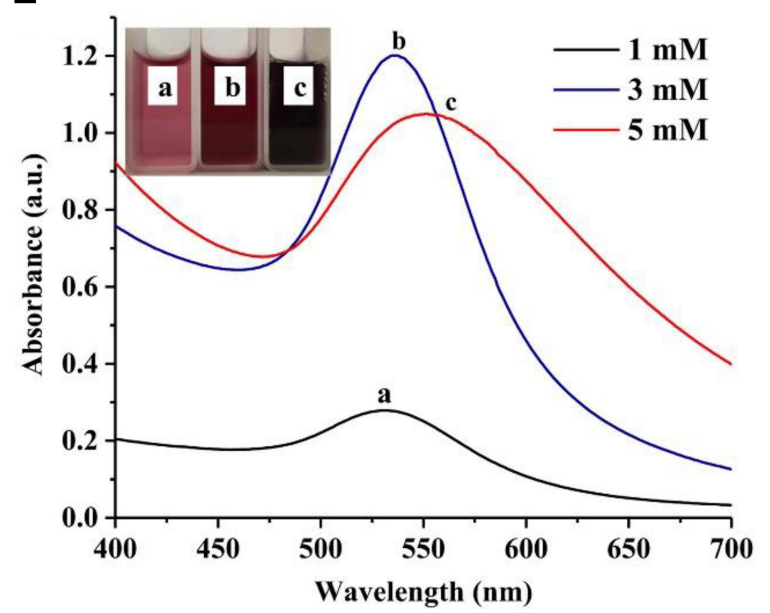

B
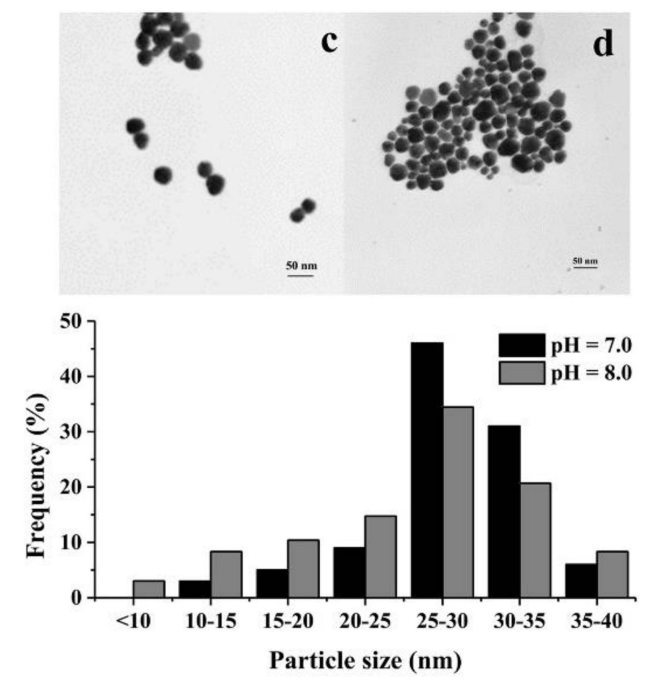

D
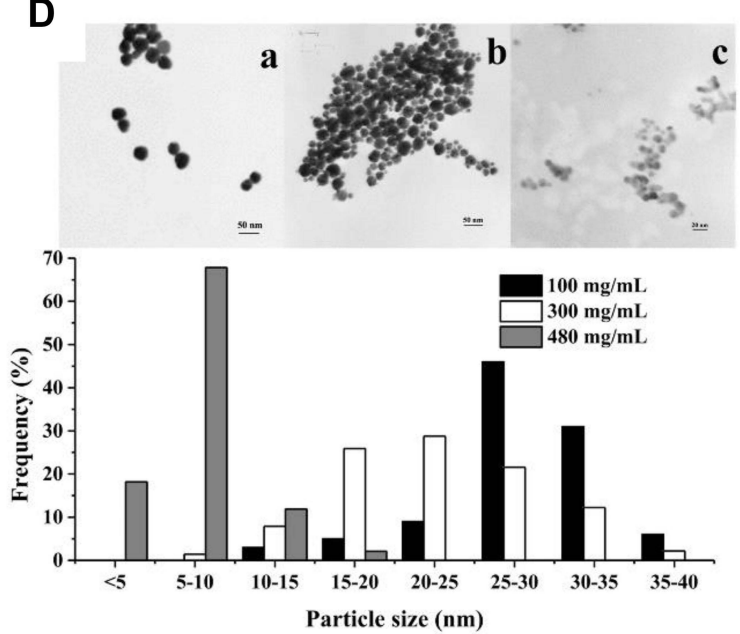

F
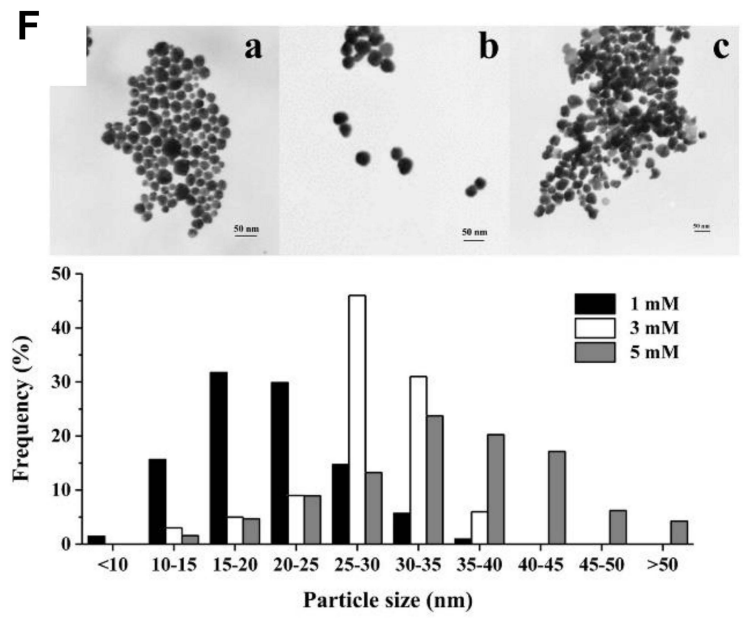

Figure 5 Green synthesis Au NPs by Aspergillum sp. (A) UV-Vis spectra of Au NPs produced extracellularly by strain WL-Au under different pH conditions. (B) TEM image and size distribution histogram of Au NPs produced extracellularly from WL-Au strain at pH 7.0 and 8.0. (C) UV-Vis spectra of Au NPs produced extracellularly by strain WL-Au using different fungi biomass concentrations. (D) TEM images and size distribution histograms of Au NPs synthesized from different biomass concentrations. ( $100 \mathrm{mg} / \mathrm{mL}, 300 \mathrm{mg} / \mathrm{mL}, 480 \mathrm{mg} / \mathrm{mL}$ ). (E) UV-Vis spectra of Au NPs produced extracellularly by strain WL-Au using different $\mathrm{HAuCl}{ }_{4}$ concentrations. (F) TEM image and size distribution histogram of Au NPs synthesized from different $\mathrm{HAuCl}_{4}$ concentrations (ImM, 3mM, 5mM). Reprinted from Phys $E$ Low-Dimensional Syst Nanostructures, 88 , Qu Y, Pei X, Shen W, et al. Biosynthesis of gold nanoparticles by Aspergillum sp. WL-Au for degradation of aromatic pollutant. I33-14I, Copyright (20I7), with permission from Elsevier. ${ }^{128}$ 
Au-S bonds. ${ }^{147,148}$ On the other hand, Au NPs synthesized using genetic material have specificity and can be selectively combined with specific molecules. ${ }^{135}$ It is expected to be widely used in the field of biomedicine. What's more, DNA-conjugated Au NPs can also be used as sensors to detect metal ions. ${ }^{149}$ Liu et al systematically studied the influence of different factors on the stability of the DNA-Au NPs. They confirmed that a higher concentration of salt solution allows DNA to adsorb on the surface of $\mathrm{Au}$ NPs faster and enhances its stability; while a lower $\mathrm{pH}$ is conducive to the formation of a dense layer of DNA on the surface of $\mathrm{Au}$ NPs; polar solution and long-chain DNA have a better protective effect on $\mathrm{Au}$ NPs. ${ }^{150}$ In recent years, a lot of work has been devoted to preparing highly stable DNA-Au NPs. Hwu et al prepared DNA-conjugated $\mathrm{Au}$ NPs and significantly improved Au NPs by regulating the density of DNA. Au NPs can still maintain excellent stability in five freeze-thaw tests $\left(-80{ }^{\circ} \mathrm{C}\right) .{ }^{151} \mathrm{Next}$, Cheng et al added biotin and diluents to different functionalized DNA adaptors to conjugated it with Au NPs and developed a new DNA-Au NPs synthesis strategy. More surprisingly, the Au conjugates prepared by this method have ultra-high stability and can still maintain a good dispersion state in the $4 \mathrm{M} \mathrm{NaCl}$ solution. The absorbance remains almost unchanged during five freeze-drying cycles. ${ }^{152}$ Besides DNA, some RNA aptamers can also modify Au NPs due to their excellent affinity and specificity. Miao et al stabilized $\mathrm{Au}$ NPs with different theophylline RNA aptamers, which showed excellent salt tolerance and remained stable under $70 \mathrm{mM} \mathrm{NaCl}$ solution. What's more, nanoparticles can quickly and accurately detect theophylline concentration in the human body. ${ }^{153}$ David et al used a self-assembly strategy to synthesize Au-siRNA NPs. It remains stable for 24 hours in $10 \%$ fetal bovine serum, so these nanoparticles are expected to serve as ideal functional probes in tumor therapy. ${ }^{154}$

\section{Synthesis High Stable Ultra-Small Au NPs}

Compared with conventional plasmonic Au NPs, ultrasmall $\mathrm{Au}$ NPs (1-3 $\mathrm{nm}$ in diameter) with atomic-level precision have different properties in optics and magnetism due to enhanced quantum size effects. ${ }^{155-157}$ Among them, photoluminescence is a unique property of ultrasmall Au NPs' surface state; It has strong emission in the NIR region due to the ultra-small size, ${ }^{158,159}$ And ultrasmall Au NPs are paramagnetic. ${ }^{160,161}$ After decades of research, people have made significant progress in preparing and applying ultra-small Au NPs. At this stage, four primary approaches are used to synthesize ultra-small $\mathrm{Au}$ NPs: bottom-up method, top-down method, dynamic control method, and green synthesis method. ${ }^{157,162-164}$

\section{Bottom-Up}

The bottom-up synthesis strategy is to use thiolates or other ligands (such as biomolecules, dendritic polymers, etc.) to protect the ultra-small Au NPs. ${ }^{165-167}$ Specifically, chloroauric acid forms a complex with a phase transfer agent, and then the ligand reduces the $\mathrm{Au}^{3+}$ in the complex to $\mathrm{Au}^{+}$. The template protects the ultra-small Au NPs from agglomeration. $^{162}$ Biomolecules and dendritic polymers are commonly used as templates. Biomolecules can synthesize ultra-small $\mathrm{Au}$ NPs under mild reaction conditions, and the products have great biocompatibility. Still, the yield of ultra-small Au NPs prepared by this method is lower. The dendritic polymer used as a hard template to prepare ultra-small $\mathrm{Au}$ NPs has a higher yield, but the disadvantages such as poor biocompatibility and longer reaction time limit its application. Nowadays, many studies show that the size of ultra-small Au NPs can be precisely controlled by adjusting the addition ratio of reducing agent and chloroauric acid to obtain size-controlled water-soluble or organic-soluble ultra-small Au NPs. ${ }^{97,168,169}$ Xie et al precisely synthesized ultra-small $\mathrm{Au}$ NPs with high quantum yields using thiol molecules as templates. ${ }^{168}$ Meanwhile, egg white has also been used to synthesize ultra-small $\mathrm{Au}$ NPs of controlled size. ${ }^{170}$

\section{Top-Down}

The top-down method is also called the etching method. It is a widely adopted synthetic strategy that enables the controlled synthesis of ultra-small Au NPs. ${ }^{171,172}$ The mechanism of this method is to etch polydisperse $\mathrm{Au}$ NPs into small-sized ultra-small Au NPs using etchants (such as dihydrolipoic acid, polyethyleneimine, etc.). ${ }^{173,174}$ In the presence of the etchant, the large $\mathrm{Au}$ NPs are continuously etched into small-sized Au NPs. Through continuous etching, the obtained ultra-small Au NPs have the most stable structure. For example, Wei et al precisely synthesized ultra-small Au NPs with good thermal stability by thiol etching in the presence of a protective agent. ${ }^{175}$ Also, some natural plant components can also be used to etch and prepare ultra-small Au NPs. Chen et al synthesis highly biocompatible ultra-small $\mathrm{Au}$ NPs by stepwise etching method using mustard acid as an etchant and reducing agent. ${ }^{176}$ 

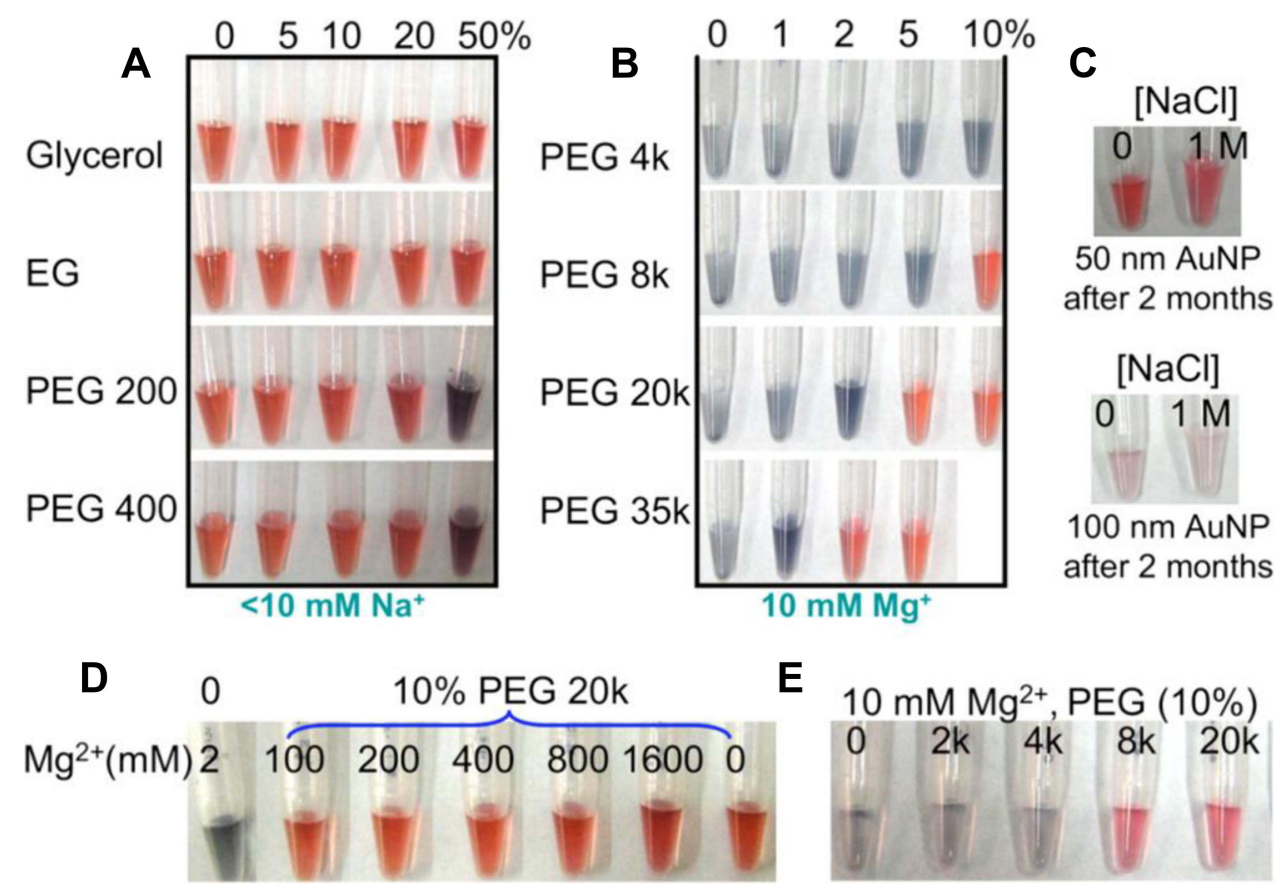

Figure 6 The stability of citrate-terminated $13 \mathrm{~nm}$ Au NPs in the presence of various solutes. (A) Aggregation begins to occur in 20\% (w/w) PEG 200 or $50 \%$ PEG 400 (no other salts added). (B) Au NPs modified with high concentration, and high molecular weight PEG remains stable in $10 \mathrm{mM} \mathrm{Mg}^{2+}$. (C) Long-term stability of Au NPs in $2 \%$ PEG 20,000. (D) $13 \mathrm{~nm}$ and (E) $50 \mathrm{~nm}$ Au NPs in the presence of various salt and PEG concentrations or molecular weights. Reprinted with permission from Zhang X, Servos MR, Liu JW. Ultrahigh Nanoparticle Stability against Salt, pH, and Solvent with Retained Surface Accessibility via Depletion Stabilization. J Am Chem Soc. 2012;134, 9910-9913. Copyright (2012) American Chemical Society. ${ }^{184}$

\section{Dynamic Control Methods}

Recently, dynamic control methods have been increasingly used for the synthesis of ultra-small Au NPs. It is based on other ways, and precise control is implemented by varying the reaction temperature and reaction time, the $\mathrm{pH}$ of the reaction system, and the concentration of the reducing agent. ${ }^{163,164}$ This method can obtain ultra-small Au NPs that meet expectations by real-time tuning. Lahtinen et al achieved a controlled synthesis of ultra-small Au NPs that are stable at different $\mathrm{pH}$ values by adjusting the ratio of methanol to water. ${ }^{169}$ Wang et al prepared ultra-small $\mathrm{Au}$ NPs protected by alkyne ligands, which can spontaneously isomerize to a more stable structure $\left(\mathrm{Au}_{23}-2 \rightarrow \mathrm{Au}_{23}-1\right)$ and have good thermal stability. ${ }^{177}$ Crudden et al first reported super-stable ultra-small $\mathrm{Au}$ NPs modified with NHC as a ligand, and the NHC-modified methyl monosubstituted ultra-small Au NPs were stable at $70{ }^{\circ} \mathrm{C}$ for more than 24 $\mathrm{h}$ due to the super-stabilizing force between the ligand and gold. $^{178}$

\section{Green Synthesis Methods}

Some new strategies for the precise synthesis of atomicscale ultra-small $\mathrm{Au}$ NPs have been reported in recent years. ${ }^{156,179,180}$ The green synthesis of ultra-small $\mathrm{Au}$ NPs mediated by natural products is one of them. ${ }^{97,99}$
Zhang et al prepared highly stable ultra-small Au NPs by a simple one-pot method using polyphenols from green tea as reducing and stabilizing agents. ${ }^{181}$ Ghosh et al successfully synthesized ultra-small Au NPs on different bacteria, in which the bacteria acted as templates and the internal proteins interacted with gold to provide stable force. This highly safe, low-cost, and rapid preparation method offers new ideas for future nanomaterial synthesis strategies. ${ }^{182}$

\section{Other Ways to Improve the Stability of Au NPs}

Some physical methods to improve the long-term stability of Au NPs after synthesis effectively. Centrifugation is one of them. Under certain conditions (7000 g, 20 minutes), the Au NPs were centrifuged and determined by DLS. The researchers found that the suspension of Au NPs can be stable for storage at $4{ }^{\circ} \mathrm{C}$ for 20 days. This study provides new ideas for improving the stability of Au NPs. ${ }^{183}$ On the flip side, high molecular weight PEG can be used to deplete and stabilize Au NPs, and achieve excellent stability under long-term storage conditions through depletion force without destroying its surface properties (Figure 6). And what is more, this method can further enrich the application of Au NPs. ${ }^{184}$ Depletion stability can be used 


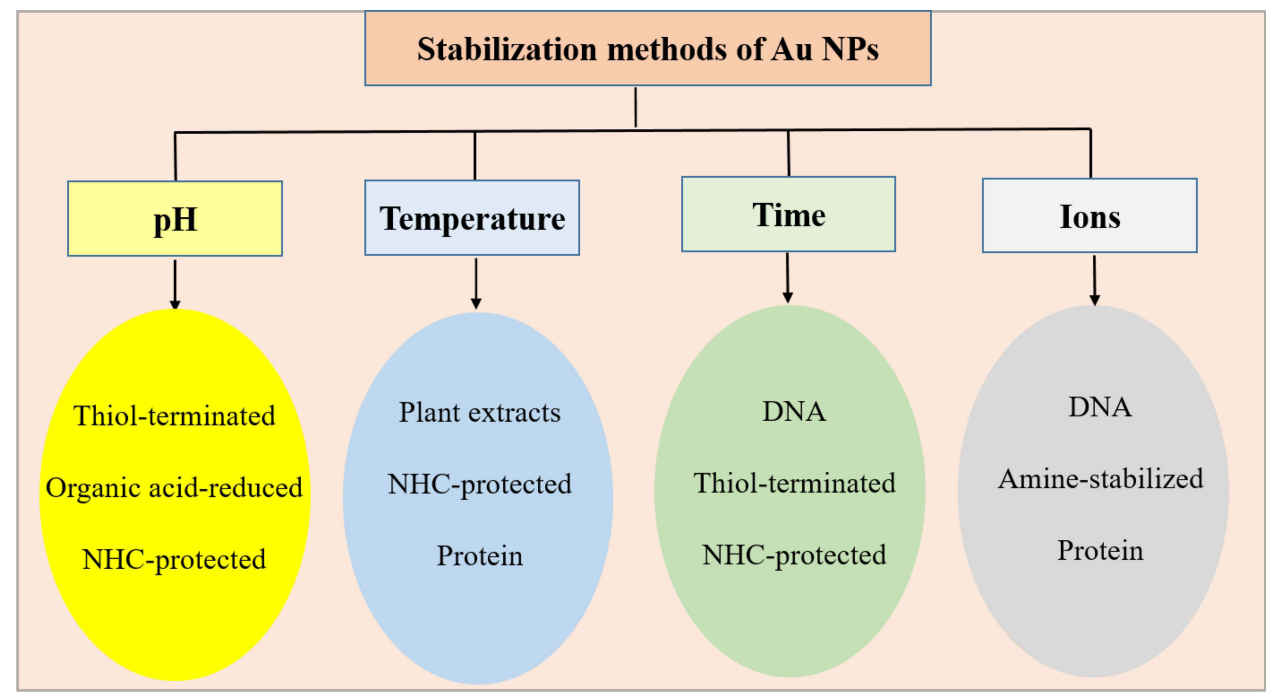

Figure 7 Various methods of stabilizing Au NPs.

as a technical means to improve the spatial stability of $\mathrm{Au}$ NPs, so that people can explore many colloidal properties and reactions for a long time.

In conclusion, conventional chemical methods may not be sufficient to protect Au NPs in some cases, causing aggregation of $\mathrm{Au}$ NPs. Currently, some polymer-modified Au NPs exhibit excellent stability under different physiological environments. For example, the superb binding ability of NHC to Au NPs has been shown to remain long-term stable in various biological media (pH, GSH, salt solution). ${ }^{69,71}$ PEG significantly improves the steric stability of the colloids, allowing the $\mathrm{Au}$ NPs to remain well dispersed under different $\mathrm{pH}$ and salt ion environments. ${ }^{185}$ Similarly, PVP-protected $\mathrm{Au}$ NPs exhibited excellent stability in some physiological environments, especially high citrate and citric acid concentrations. $^{87,185}$ Natural product-mediated green synthesis of $\mathrm{Au}$ NPs can remain stable under long-term storage, and modified by biomolecules (proteins and DNA) can remain stable for a long time under biological substrates and extreme temperatures. The various stabilization methods of $\mathrm{Au}$ NPs are shown in Figure 7. And we give various stabilizers used during various synthesis methods in Table 1. At this stage, due to $\mathrm{Au}$ NPs with long-term stability and satisfactory stability in ionic solution and biomatrix, their application prospects in biomedicine are receiving more and more attention.

\section{Application of Au NPs in Biomedicine}

At present, because of the continuous in-depth research on $\mathrm{Au}$ NPs, it occupies a vital position in biomedicine. Due to the smaller size of Au NPs, they can accumulate in tumor tissues in the biomedical field. It is called enhanced penetration and retention effect (EPR), which helps achieve better therapeutic effects. ${ }^{186}$ And the unique physical and chemical properties of Au NPs, there are bright prospects in nanomedicine. ${ }^{179,187-190}$ Herein, we focus on the most recent studies in biomedicine, including drug delivery vehicles, bioimaging, PTT, clinical diagnosis, nanozymes, RT, and other application.

\section{Drug Delivery}

Drug chemotherapy is a primary clinical treatment method. However, it has obvious disadvantages: First, some drug's poor solubility and stability inhibit the therapeutic effect. More importantly, the direct administration method cannot enrich the medicine at the tumor site, thereby weakening the drug's efficacy and causing many side effects to the body. Therefore, there is an urgent need for a carrier to load the drug to extend its blood half-life and protect its activity to achieve enrichment and controlled release at the tumor site. Due to its easy-to-control size, active surface chemical properties, and good biocompatibility, Au NPs are widely used as an ideal carrier for drug delivery. ${ }^{191}$ We can achieve drug delivery by 
Table I Preparation of Highly Stable Au NPs

\begin{tabular}{|c|c|c|c|c|c|c|}
\hline Stabilizing Agent & Synthesis Method & $\mathbf{p H}$ & Time & $\begin{array}{c}\text { Stability } \\
\text { Temperature }\end{array}$ & lons Stress & Ref. \\
\hline \multirow[t]{2}{*}{ Bidentate NHC } & \multirow[t]{2}{*}{ Brust-Schiffrin method } & \multirow[t]{2}{*}{-} & \multirow[t]{2}{*}{ - } & $130^{\circ} \mathrm{C}$ & $5 \mathrm{mM}$ DDT & \multirow[t]{2}{*}{ [63] } \\
\hline & & & & & I $\mathrm{mM}$ thiophenol & \\
\hline PPy & Seed-mediated method & $1-9$ & I year & $50^{\circ} \mathrm{C}$ & - & [74] \\
\hline PDMAEMA & \multirow[t]{2}{*}{ One-step synthesis } & \multirow[t]{2}{*}{-} & \multirow[t]{2}{*}{6 months } & \multirow[t]{2}{*}{ - } & $2 \mathrm{M} \mathrm{NaCl}$ & \multirow[t]{2}{*}{ [80] } \\
\hline PEG/EG & & & & & 3 M DTT & \\
\hline \multicolumn{2}{|c|}{ PEG Physical sputtering method } & - & - & $100^{\circ} \mathrm{C}$ & - & [8। \\
\hline PVP K30 & Chemical reduction & - & 6weeks & - & - & [87] \\
\hline PAH & Chemical reduction & - & $>1$ month & _- & - & [88] \\
\hline \multirow[t]{3}{*}{ DHLA } & \multirow[t]{3}{*}{ Chemical reduction } & \multirow[t]{3}{*}{-} & 50 days & $4^{\circ} \mathrm{C}$ & PBS & \multirow[t]{3}{*}{ [9। } \\
\hline & & & - & - & $\mathrm{I} \mathrm{M} \mathrm{NaCl}$ & \\
\hline & & & & & 0.1 M DTT & \\
\hline EDTMP & One pot method & $3-12$ & 3 months & - & $25 \mathrm{mM}$ PBS & [94] \\
\hline PEG & \multirow[t]{2}{*}{ Chemical reduction } & $2.5-11$ & \multirow[t]{2}{*}{ - } & $-78-48^{\circ} \mathrm{C}$ & \multirow[t]{2}{*}{ - } & \multirow[t]{2}{*}{ [95] } \\
\hline DCA & & & & & & \\
\hline CA & Self-assembly & - & $>3$ months & - & - & [96] \\
\hline GA & \multirow[t]{3}{*}{ Chemical reduction } & \multirow[t]{3}{*}{-} & & \multirow[t]{3}{*}{-} & \multirow[t]{3}{*}{-} & \multirow[t]{3}{*}[107]{} \\
\hline PCA & & & 3 months & & & \\
\hline IF & & & & & & \\
\hline Starch & \multirow[t]{2}{*}{ Chemical reduction } & \multirow[t]{2}{*}{ - } & \multirow[t]{2}{*}{ >I year } & \multirow[t]{2}{*}{ - } & \multirow[t]{2}{*}{-} & {$[114]$} \\
\hline Glucose & & & & & & \\
\hline Extract of mango leaves & Hydrothermal & - & $>5$ months & - & - & {$[119]$} \\
\hline Gum Arabic & Chemical reduction & - & 5 weeks & - & - & {$[121]$} \\
\hline Glycan & Ligand exchange & - & - & - & $0.07 \mathrm{~g} / \mathrm{mL}$ serum & {$[122]$} \\
\hline PEG 20K & Chemical reduction & - & - & $63^{\circ} \mathrm{C}$ & $500 \mathrm{mM} \mathrm{NaCl}$ & {$[134]$} \\
\hline Choline & & & & & & \\
\hline TEA & Two-step synthesis & - & - & - & $200 \mu \mathrm{L} / \mathrm{mL} \mathrm{Hbs}$ & {$[139]$} \\
\hline Tryptophan & & & & & & \\
\hline Thermo ferritin & Self-assembly & - & - & $62.5^{\circ} \mathrm{C}$ & $800 \mathrm{mM} \mathrm{NaCl}$ & {$[140]$} \\
\hline Keratin & Chemical reduction & - & 6 months & $4^{\circ} \mathrm{C}$ & - & {$[141]$} \\
\hline Albumin & & & & & & \\
\hline $\begin{array}{l}\text { Protein extract of } \\
\text { Rhizopus oryzae cells }\end{array}$ & One-pot synthesis & - & - & - & $\begin{array}{c}\text { I00mM (PBS, Bicarbonate, Tris- } \\
\text { HCl, HEPES, PIPES) }\end{array}$ & {$[143]$} \\
\hline DNA & Covalent binding method & - & - & $-80^{\circ} \mathrm{C}$ & - & {$[151]$} \\
\hline
\end{tabular}


Table I (Continued).

\begin{tabular}{|c|c|c|c|c|c|c|}
\hline Stabilizing Agent & Synthesis Method & $\mathrm{pH}$ & Time & $\begin{array}{c}\text { Stability } \\
\text { Temperature }\end{array}$ & Ions Stress & Ref. \\
\hline Biotin, DNA & $\begin{array}{l}\text { Au-S bond and DNA } \\
\text { assembly }\end{array}$ & - & - & $-80^{\circ} \mathrm{C}$ & $4 \mathrm{M} \mathrm{NaCl}$ & [152] \\
\hline RNA aptamer & RNA interacts with Au NPs & - & - & - & $70 \mathrm{mM} \mathrm{NaCl}$ & [153] \\
\hline si RNA & $\begin{array}{l}\text { RNA hybridization on the } \\
\text { surface of Au NPs }\end{array}$ & - & - & - & $10 \% \mathrm{FBS}$ & [154] \\
\hline$\rho M B A-$ thiolate & Wet chemical synthesis & - & $>6$ months & - & - & [169] \\
\hline $\mathrm{NHC}$ & Coordination substitution & - & $24 \mathrm{~h}$ & $70^{\circ} \mathrm{C}$ & - & [178] \\
\hline Extract of Green tea & Green reduction & _ & 7 days & _ & _ & {$[181]$} \\
\hline
\end{tabular}

combining drugs with Au NPs by physical embedding or chemical bonding. Given this, Tan et al conjugated specific DNA aptamers to Au NPs through self-assembly. They loaded doxorubicin (DOX) on the surface of the nanocomposite to achieve controlled drug release under NIR irradiation. ${ }^{192}$ Chen et al directly couple Au NPs with methotrexate (MTX) to form a nanocomposite released in lung tumor tissues to achieve enhanced therapeutic effects. ${ }^{193}$ Sulaiman et al load biologically active hesperidin inside Au NPs by simple stirring. This drug delivery system with good biocompatibility can significantly inhibit the growth of human breast cancer cells and effectively relieve inflammation. ${ }^{194}$ For drug delivery systems based on Au NPs, some specific substances (such as folic acid, red blood cell membrane, neutrophil membrane, etc.) can modify on the surface of Au NPs to achieve targeted therapy and obtain better curative effects. ${ }^{195}$ For example, Au NPs co-protected by PEG and 4-mercaptobenzoic acid (MBA) can be used as targeting carriers to deliver DOX, thereby significantly improving the therapeutic effect on breast cancer. ${ }^{196}$ Besides, due to the high photothermal conversion efficiency of $\mathrm{Au} \mathrm{NPs,} \mathrm{it} \mathrm{also} \mathrm{has} \mathrm{a} \mathrm{synergistic}$ effect on the photothermal treatment of tumors while delivering drugs. Studies have shown that DOX is loaded into the Au nanocage wrapped by the cancer cell membrane. The composite nanomaterial can achieve high-efficiency delivery of DOX and cause breast cancer cell apoptosis through auxiliary NIR irradiation. ${ }^{197}$ At present, with the continuous deepening of research, we have discovered that in addition to serving as a drug delivery carrier alone, $\mathrm{Au}$ NPs can also be conjugated with other substances to form composite materials to exert their advantages further. It mainly includes some responsive polymers, proteins, and inorganic nanomaterials. As a universal heat-sensitive polymer, poly ( $\mathrm{N}$-isopropyl acrylamide) can combine with rod-shaped Au NPs as a drug delivery vehicle. This responsive polymer can effectively reduce the toxicity of the loaded drug, and the drug also has a controllable release rate when the NIR irradiates the carrier. ${ }^{198}$ For protein, Mi-RNA can be combined with Au NPs to release Mi-RNA in tumor cells with high glutathione concentrations, thereby realizing efficient gene therapy. ${ }^{199}$ And Au NPs can hybridize with iron to prepare composite nanoparticles with a metal-organic framework (MOF) structure. Au-MOF NPs can be loaded with camptothecin, and the structure is destroyed under the exceptional physiological environment of the tumor to release the drug. What is more surprising is that the produced $\mathrm{OH}^{\cdot}$ can further activate the Fenton reaction and achieve synergistic therapy. ${ }^{200}$ Besides, a novel drug delivery system was developed by Zhu et al. They loaded vancomycin onto ultra-small Au NPs to achieve controlled release of the drug and allowed real-time monitoring of the release process by the generated fluorescent signals. This research provides new ideas for Au NPs in a multifunctional platform based on drug delivery. ${ }^{180}$

\section{Bioimaging}

The main biomedical imaging methods are magnetic resonance imaging, CT imaging, and photoacoustic imaging. ${ }^{201,202}$ These imaging methods require a contrast agent to enter body tissues or organs to improve image contrast and imaging effect due to the long half-life of nanomaterials in the blood, increasing the accuracy and specificity of imaging. Nowadays, more and more nanomaterials applications are used in bioimaging. ${ }^{201,203,204}$ Among 
them, Au NPs have become one of the current ideal contrast agent candidates in bioinaging methods. In CT imaging, compared with traditional contrast agents, $\mathrm{Au}$ NPs have the advantages of high biocompatibility, low toxicity, and easy functionalization. What's more, the high X-ray absorption coefficient and high contrast of Au NPs make it an ideal material for contrast agents. ${ }^{205}$ Under certain conditions, the X-ray decay rate of Au NPs with the same concentration is five times slower than iodine. ${ }^{206}$ More importantly, we can design suitable modifiers to functionalize the surface of Au NPs for targeted delivery to the organs and tissues that need to be imaged, thereby improving the imaging effect. ${ }^{207}$ At present, there are more and more applications of Au NPs in contrast agents. Due to the complex physiological environment in the blood, it is often necessary to modify other substances to enhance their stability when synthesizing Au NPs as contrast agents. Studies have shown that PEG-modified small-size Au NPs (38 nm) have excellent stability, increasing blood half-life, is an ideal contrast agents in the blood. It has obvious advantages with the traditional contrast agent iodine. ${ }^{208}$ Next, new research confirms that $\mathrm{Au}$ NPs functionalized with glutamic acid can be used as contrast agents due to their large X-ray attenuation coefficient and excellent stability under physiological conditions. ${ }^{209}$ In addition to being used as conventional contrast agents, Au NPs can also be used for targeted imaging. For instance, Sun et al synthesized Au NPs coated with glycol chitosan, which can specifically CT imaging of tumors in the liver. Currently, Au NPs synthesized from some natural products can also be used as X-ray contrast agents. For example, Au NPs stabilized and reduced by gum arabic show excellent biocompatibility and remain stable in electrolyte solutions $(2 \mathrm{M} \mathrm{NaCl})$ and serum solution $(1 \mathrm{mg} / \mathrm{mL}$ HSA or $1 \mathrm{mg} / \mathrm{mL}$ BSA). Furthermore, the contrast agent effect of GA-Au NPs is about three times that of iodixanol at a similar concentration. ${ }^{210}$ Photoacoustic imaging combines optical imaging and ultrasound imaging, is an emerging non-invasive imaging technology with high resolution and strong tissue penetration depth. ${ }^{211}$ Due to the LSPR effect, controlled size, and high photothermal conversion capability of Au NPs, it has wide application foreground in photoacoustic imaging. Tan et al constructed a highly specific gold-coated $@ \mathrm{Fe}_{3} \mathrm{O}_{4}$ multifunctional nano-platform, which can realize the functions of magnetic resonance imaging, photothermal therapy. ${ }^{212}$ At this stage, many groups have confirmed that Au NPs have great imaging effects as a contrast agent for photoacoustic imaging. Chen et al synthesized small-sized rod-shaped Au NPs (50nm) by seed-mediated method, which has extreme tumor penetration efficiency and can generate photoacoustics 3.5 times stronger signal than conventional-sized $\mathrm{Au}$ nanorods $(130 \mathrm{~nm}){ }^{8}$ Zhang et al developed PEG-modified $\mathrm{Au}$ NPs $(20-50 \mathrm{~nm})$, which can be effectively enriched in tumor tissues and achieve excellent photoacoustic imaging effects. $^{213}$ On the other hand, luminescent ultra-small Au NPs have an easily tunable size, surface functionalization, and superior safety making them one of the best candidates for bioimaging. And among them, some biomolecule-modified ultra small Au NPs are of great interest due to their specifical targeting and efficient renal clearance efficiency. ${ }^{158}$ For example, the ultra-small Au NPs synthesized by mercapto-cyclodextrin have excellent luminescence properties, with maximum excitation intensity at $1050 \mathrm{~nm}$. Surprisingly, imaging was still possible even at a concentration of $1 \mu \mathrm{M}$. And follow-up studies have shown that ultra-small Au NPs synthesized by this method also have promising applications in protein labeling for tumortargeted imaging. ${ }^{214}$ Zhang et al prepared excellent biocompatible ultra-small Au NPs doped with other atoms using glutathione. The ultra-small size enables Au NPs to have a greater penetration depth $(0.61 \mathrm{~cm})$, while other atoms $(\mathrm{Cu}, \mathrm{Zn})$ make ultra-small $\mathrm{Au}$ NPs have better imaging effects, thereby realizing multifunctional real-time imaging in vivo. ${ }^{215}$ Chen et al successfully built a nano platform for integrated treatment. The nanoplatform enable dual-mode imaging of NIR fluorescence and CT as a bioprobe, and the excellent photothermal conversion efficiency enables it to be used for photothermal therapy. ${ }^{216}$

\section{Photothermal Therapy}

While traditional hyperthermia destroys tumor tissues, it also damages normal tissues. As a non-invasive treatment method, photothermal therapy uses nanoparticles as a photothermal therapy agent to irradiate the tumor with a NIR $(808 \mathrm{~nm})$, which can accurately destroy tumor tissues without damaging normal tissues. ${ }^{217}$ This method can effectively reduce the side effects of treatment. As one of the most critical inorganic nanomaterials in biomedicine, Au NPs play an essential role in photothermal therapy. Due to the high light-to-heat conversion efficiency of Au NPs, strong absorption of NIR, LSPR effect, and easy-to-control size and shape. Generally, Au NPs are used in photothermal therapy in two ways. One is to use pure Au NPs as a photothermal agent; the other is to form a composite material with some substances or load drugs for synergistic treatment. Because of this, Depciuch et al explored the photothermal treatment effect of Au NPs and found that it 

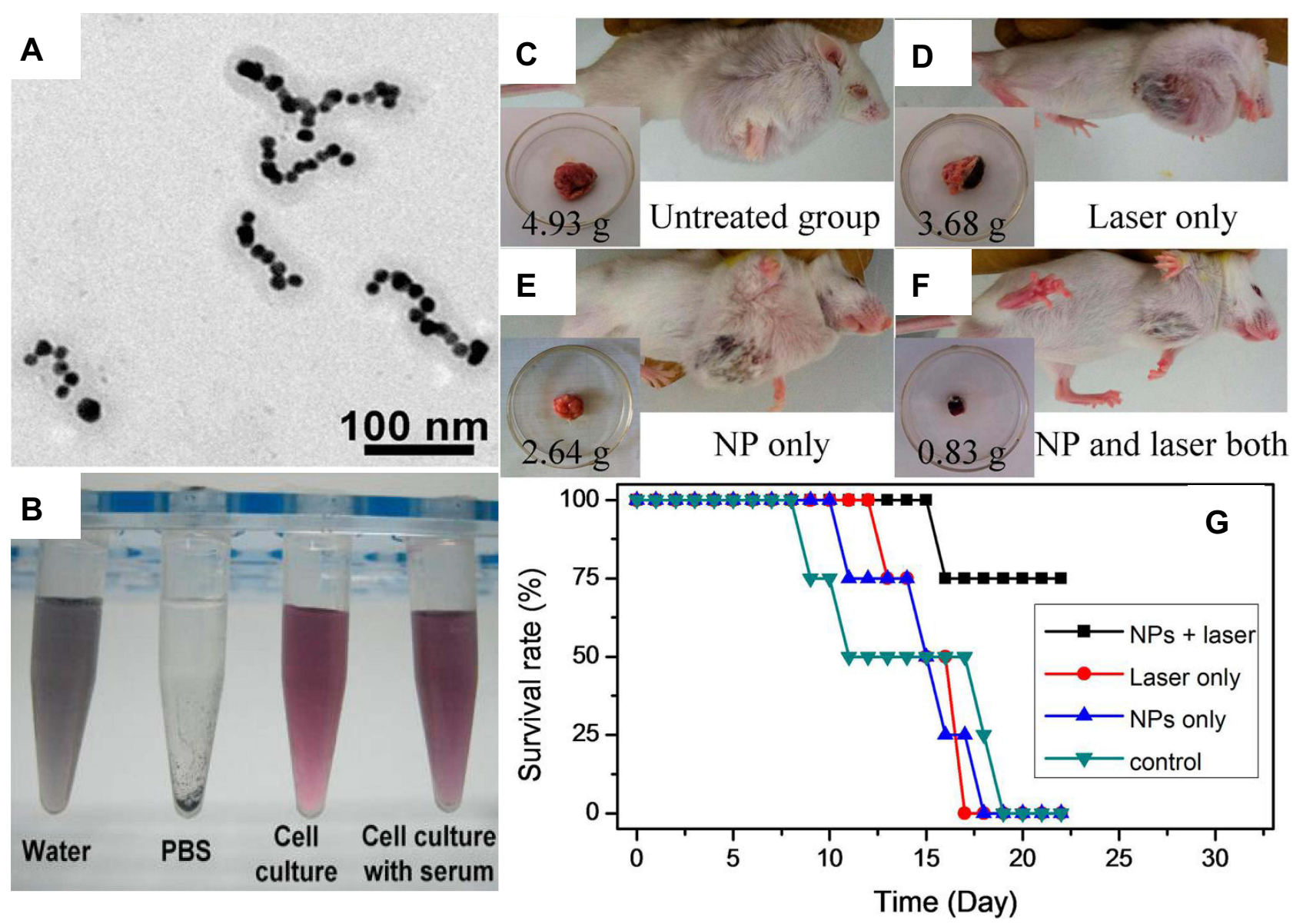

Figure 8 In vivo photothermal therapy by PPy-coated Au chains. (A) TEM image of Au NPs coated by PPy. (B) PPy-coated Au chains can keep stable both in water and cell culture after 7 days of incubation. (C-F) Typical photographs for four groups with different treated additions. (C) Untreated. (D) Only laser irradiated. (E) Only NP injected. (F) Both laser irradiated and NP injected. Insets: tumor photographs and weight after 14 days were recorded, and (G) survival rate of the mice for four groups. Reprinted with permission from Lin M, Guo CR, Li J, et al. Polypyrrole-Coated Chainlike Gold Nanoparticle Architectures with the 808 nm Photothermal Transduction Efficiency up to 70\%. ACS Appl Mater. 2014;6:5860-5868, Copyright (2014), American Chemical Society. ${ }^{220}$

can significantly inhibit colon cancer cells; the cell viability after $808 \mathrm{~nm}$ laser irradiation for 5 minutes is only about $50 \%{ }^{218}$ Besides, the rod-shaped Au NPs have excellent photothermal treatment effects due to their extreme high extinction coefficient. Studies have shown that PEG-modified rod-shaped Au NPs can exert therapeutic effects within 72 hours and eliminate breast tumors in mice within 10 days. ${ }^{219}$ Nowadays, research on photothermal therapy has turned to Au-based composite nanomaterials. We can modify the surface of $\mathrm{Au}$ NPs to achieve specific functions. These hybrid nanomaterials can be combined with drugs or doped with other substances to enhance the photothermal treatment effect further. For example, encapsulated by PPy exhibits ultrahigh light-to-heat conversion efficiency $(70 \%)$ due to its unique chain structure and self-assembly behavior. Subsequent experiments have also confirmed that it can achieve an excellent tumor photothermal ablation effect under the irradiation of
$808 \mathrm{~nm}$ NIR (Figure 8). ${ }^{220}$ Next, the latest research shows that the Au@Pt composite dendritic NPs synthesized by ultrasound have the characteristics of $\mathrm{Au}$ and $\mathrm{Pt}$ at the same time. Therefore, the high photothermal conversion efficiency of $\mathrm{Au}$ and the photothermal stability of Pt make this composite become an ideal material for photothermal therapy. ${ }^{221}$ Moreover, adding photosensitizer can further enhance the photothermal treatment effect. For example, porphyrin derivatives are used as photosensitizers to couple with Au NPs to generate singlet oxygen during the heating process to kill cancer cells effectively. This method can achieve high-efficiency photothermal treatment effects. ${ }^{222}$

\section{Clinical Diagnosis}

Compared with traditional clinical methods, nanosystems based on noble metals can be quickly and accurately used for biomedical diagnosis, which has received extensive 

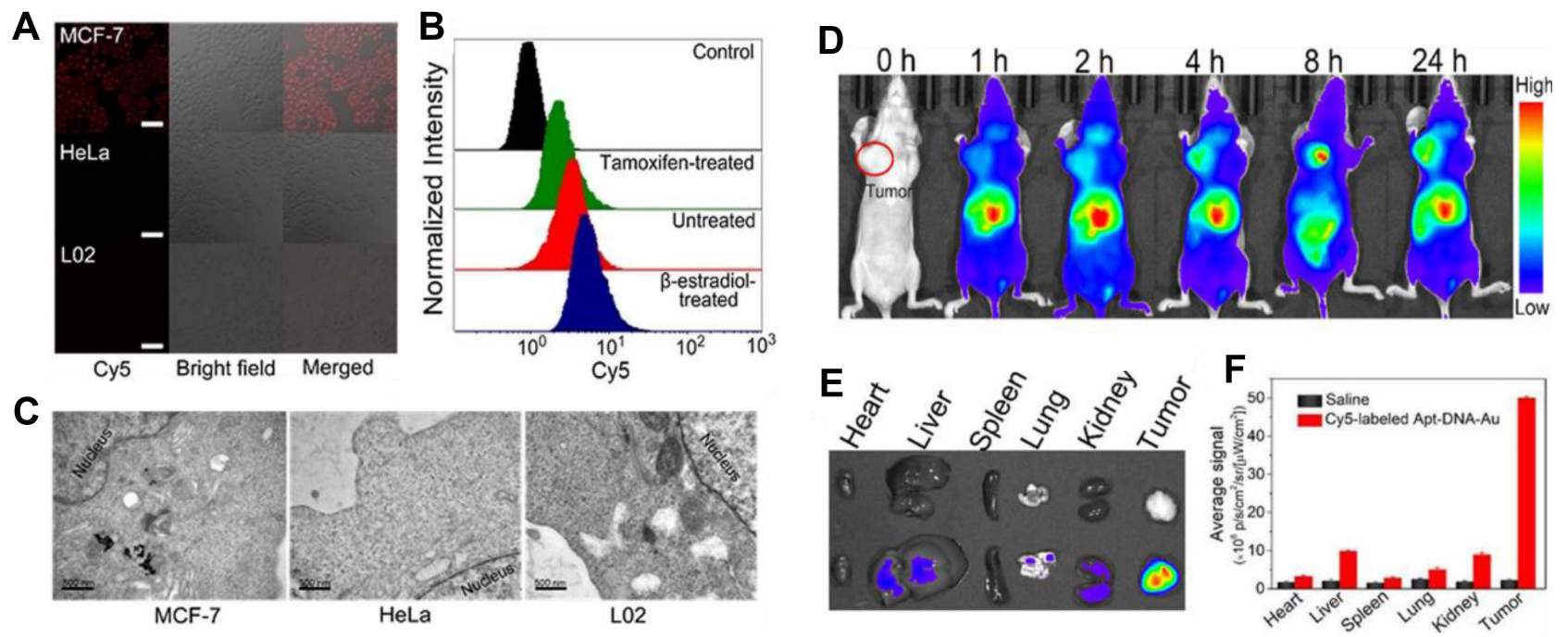

Figure 9 Multifunctional aptamer-linked DNA-Au nanomachine (Apt-DNA-Au) (A) TEM and (C) CLSM images of the states of Au NPs in MCF-7 cells, HeLa cells, and L02 cells, respectively, after incubation with Cy5-labeled Apt-DNA-Au nanomachine. Scale bar: $100 \mu \mathrm{m}$. (B) The results of different expression levels of TKI mRNA in MCF-7 cells by flow cytometry. Scale bar: $100 \mu \mathrm{m}$. (D) In vivo fluorescence imaging of Apt-DNA-Au nanomachine at different times. (E) In vivo fluorescence imaging of organs and tumors treated with saline (top) and Apt-DNA-Au nanomachines (bottom). (F) The signal intensity of different organs and tumors. Reproduced from Yu S, Zhou Y, Sun Y, et al. Endogenous mRNA Triggered DNA-Au Nanomachine for in Situ Imaging and Targeted Multimodal Synergistic Cancer Therapy. Angew Chemie Int Ed. 202 I;60(I I): 59485958. @ 2020 Wiley-VCH GmbH. ${ }^{228}$

attention in recent years. And Au NPs are one of them; due to their superior biocompatibility, unique physical and chemical properties, Au NPs are increasingly used as diagnostic tools (such as biosensors or nanoprobes) to test some clinical indicators. On the one hand, specific oligonucleotides can be integrated on Au NP to identify sequence-specific DNA or RNA in the sample to be tested, which can be identified and analyzed by methods such as colorimetry and fluorescence detection. ${ }^{223-225}$ On the other hand, owing to the LSPR effect and Raman scattering properties of Au NPs, it can enhance or amplify the SPR signal, so they are often used to detect the level of biomarkers of certain diseases to achieve a rapid diagnosis. ${ }^{26,227}$ In recent years, many researchers are committed to building a platform based on Au NPs for fast and accurate diagnosis of some clinical indicators. Zhu et al developed a multifunctional nanosystem that can real-time monitor breast cancer changes in vivo. They hybridized specific aptamers with fluorescent DNA strands, combined with $\mathrm{Au}$ NPs through Au-S bonds. Finally, they loaded drugs into nanosystems to achieve various functions such as fluorescence monitoring of tumor cell expression, drug delivery, and photothermal therapy (Figure 9). ${ }^{228}$ Nietzold et al prepared $\mathrm{Au}$ NPs with a diameter of 20-60 nm, then fixed anti- $\alpha$-fetoprotein on the surface of Au NPs, and constructed a nanoprobe for the rapid detection of tumor marker $\alpha$-fetoprotein, which can detect the concentration of $\alpha$-fetoprotein in the serum of $0.1-0.4 \mu \mathrm{g} \cdot \mathrm{mL}^{-1} \cdot{ }^{229}$ In addition, specific DNA aptamers can be conjugated with Au NPs are used as probes to detect the cancer cell marker proteins PDGF and VEGF at the $\mathrm{nM}$ level using colorimetry and fluorescence methods. ${ }^{230}$ At this stage, compared with conventional clinical diagnosis methods, based on Au NPs test tools, can provide better results. For example, Au NPs can detect hepatoma up-regulated protein RNA in human urine, thereby realizing early diagnosis of bladder cancer. What is more surprising is that this low-cost diagnosis method has strong specificity (88.5\%) and sensitivity (94\%), a low detection limit, even the detection effect exceeds that of conventional PCR testing. ${ }^{231}$ Gordon et al prepared polystyrene-modified rod-shaped Au NPs, which can quickly detect the signal intensity of Raman spectroscopy in urine, and quantitatively analyzing the representative tumor marker Acetyl Amantadine (AcAm), with a detection limit of $16 \mathrm{ng} / \mathrm{mL}^{232}$ Besides, using Au NPs to construct microchips to detect the level of some biomarkers in the blood is also a hot spot in current research. The latest research shows that a new type of diagnosis technology uses electrically activated nanoflow chips to capture the biomarker extracellular vesicles (EVs) released by melanoma cells in the blood. Simultaneously, it can combine with a particular type of Au NPs attached to an antibody, which can adsorb unique molecules on melanoma cell EVs' surface. This 
method is expected to achieve early diagnosis and treatment of cancer. ${ }^{233}$ Recently, research reports functionalized ultra small Au NPs can diagnose $100 \%$ of human immunodeficiency virus (HIV) through antigen-antibody interactions. More surprisingly, this immunoassay method can achieves pico-level sensitivity. This method opened up the new way for early clinical diagnosis based on $\mathrm{Au}$ NPs. ${ }^{234}$

\section{Nanozyme}

The unique enzyme-like activity of ultra-small Au NPs, the catalytic sites on their surface, and their good stability and biocompatibility give them potential as nanozymes in biomedicine. ${ }^{235-237}$ For instance, dendritic polymer PAMAM-modified ultra-small Au NPs can autocatalyze the decomposition of hydrogen peroxide to oxygen in an acidic environment, achieve enhanced photodynamic therapeutic effects in combination with photosensitizers. ${ }^{238}$ Atomically engineered ultra-small $\mathrm{Au}$ NPs can meet the expectation of having enzymelike activity while maintaining high stability, resulting in efficient antioxidant activity and catalytic activity. ${ }^{239}$ Precise synthesis of highly selective atomic-level artificial enzymes have become a hot research topic in recent years. Zhang et al developed gold-based nanozymes. And the nanozymes possess CAT and SOD enzyme activities, which can significantly reduce the reactive oxygen species content and alleviate neuroinflammation. ${ }^{240}$ Recent studies have shown that the atomic-level $\mathrm{Au}_{24} \mathrm{Ag}_{1}$ cluster enzyme has ultra-high physiological stability and its unique CAT and GPxlike enzyme activities can effectively inhibit inflammatory molecules in the brain, which is expected to play an essential role in nanomedicine. ${ }^{241}$

On the other side, antibacterial is an essential property of nanozymes. Ultra-small size $(<2 \mathrm{~nm}) \mathrm{Au}$ NPs have been found to interact with bacteria and destroy their cell membrane. They exhibit significant antibacterial activity, which is not found in conventional size Au NPs. ${ }^{242-244}$ Because of this, Xie et al synthesized ultra-small Au NPs with 6-mercaptohexanoic acid as ligand and systematically investigated their antibacterial activity. They found that ultra-small Au NPs $(<2$ $\mathrm{nm}$ ) killed more than $90 \%$ of Staphylococcus aureus, Staphylococcus epidermidis, Bacillus subtilis, Escherichia coli, and Pseudomonas aeruginosa, and further studies confirmed that it was due to the ability of ultra-small $\mathrm{Au} \mathrm{NPs}$ to induce the production of
ROS. $^{245}$ Apart from that, Gu et al synthesized ultrasmall Au NPs by a simple one-step method, which can promote the release of ROS within Clostridium difficile and disrupt its cell membrane, and is expected to serve as a new avenue for the treatment of Clostridium difficile infection. ${ }^{246}$ Besides, Au NPs prepared from Gloriosa superba leaf extracts can interact with biological membranes, leading to cell death, exhibiting significant antibacterial activity, and promising as a treatment for microbial infections drugs. ${ }^{247}$ Chopade et al used the extract of Plumbago zeylanica facile synthesis Au NPs, which exhibited remarkable antibacterial effects against many bacteria. ${ }^{110}$

\section{Cancer Radiotherapy}

Similar to $\mathrm{Au} \mathrm{NPs,} \mathrm{ultra-small} \mathrm{Au} \mathrm{NPs} \mathrm{also} \mathrm{play} \mathrm{an}$ essential role in the treatment of tumors. ${ }^{179}$ The excellent safety profile of ultra-small Au NPs, the long blood half-life, and the enhanced EPR effect due to their small size in the body, creating the conditions for their use in tumor radiotherapy. On the other hand, because of the larger atomic number, gold has stronger absorption for radiation, so it is an ideal radiosensitizer. ${ }^{248,249}$ Given this, Xie et al designed a novel glutathione ultra-small Au NPs radiotherapy agent, in which glutathione can significantly enhance the accumulation of the drug at the tumor site. At the same time, the stronger absorption ability of gold to radiation can effectively improve the radiotherapy effect. $^{250}$ Basilion et al synthesized PSMA peptidemodified ultra-small Au NPs in situ; they confirmed that the targeted ultra-small Au NPs significantly inhibited tumor growth in the presence of radiotherapy compared to controls. ${ }^{251}$ Xing et al first prepared ultra-small Au NPs with cyclic RGD peptide as a template, which maintained excellent stability in different physiological environments (DMEM medium, FBS serum, etc.), and next they confirmed the enhanced radiosensitizing effect and specific targeting ability of ultra-small Au NPs by animal experiments, and tumor growth was significantly inhibited after treatment. ${ }^{252} \mathrm{Kim}$ et al used $\mathrm{Au}$ NPs as a radiosensitizer for radiotherapy of melanoma. They found that the nanoparticles were effective in killing cancer cells and inhibiting their growth in the presence of X-rays, and further enriching the application of $\mathrm{Au}$ NPs in cancer radiotherapy. ${ }^{253}$ 


\section{Other Biomedical Application}

$\mathrm{Au}$ NPs have a wide range of applications in gene therapy, photodynamic therapy, etc. ${ }^{254,255}$ For example, $\mathrm{Xu}$ et al synthesized chitosan-coated $\mathrm{Au}$ NPs, which can carry the p53 gene and treat breast cancer cells efficiently. More critically, this nanoplatform enables photothermal/gene therapy as well as real-time imaging. ${ }^{256}$ Russell's group prepared lactose-modified targeted Au NPs, and that significantly improved the hydrophobicity of the photosensitizer zinc phthalide turnip. This synthesis method can enhance photodynamic therapeutic effects with $90 \%$ cytotoxicity against human breast cancer cells SK-BR-3. ${ }^{257}$ These examples further demonstrate the enormous potential of Au NPs in biomedicine.

\section{Conclusion and Perspective}

In this review, we overview various strategies for preparing highly stable $\mathrm{Au}$ NPs: polymer-protected method, green synthesis method, and size-controlled method, which have promising applications in drug delivery, bioimaging, photothermal therapy, clinical diagnostics, nanozyme, clinical diagnosis and other biomedical applications due to their excellent biocompatibility and stability under various physiological environment.

However, there are still many challenges in the preparation and biomedicine application of highly stable Au NPs. Conventional chemical methods require some reagents as reducing or protective agents to help synthesize $\mathrm{Au} \mathrm{NP}$, but these solvents are difficult to remove after the reaction. In in vivo biological applications, high doses of $\mathrm{Au}$ NPs are often required to meet their therapeutic effects in drug delivery, bioimaging, nanozyme, radiotherapy and photothermal therapy of cancer. Regretfully, the toxicity of high doses of $\mathrm{Au}$ NPs to the organism is unclear, and further clinical studies are needed. On the other hand, for bioimaging and early clinical diagnosis, it is essential to continue to improve the sensitivity and specificity of Au NPs as probes to achieve accurate and rapid imaging and diagnosis in complex body fluid environments.

In conclusion, we believe that the synthesis strategy of highly stable Au NPs further developed and functionalized to meet the application in biomedicine, thereby making remarkable contributions to human health.

\section{Acknowledgments}

This work was supported by the Natural Science Foundation of Xinjiang (No. 2019D01C054, No. 2018D01C040), National Natural Science Foundation of China (No: 31960496), Tianshan Innovation Team Project in Xinjiang Autonomous Region (2020D14022) and the research start-up fund of Xinjiang University (No. 4305050102H6).

\section{Disclosure}

The authors report no conflicts of interest in this work.

\section{References}

1. Daniel MC, Astruc D. Gold nanoparticles: assembly, supramolecular chemistry, quantum-size-related properties, and applications toward biology, catalysis, and nanotechnology. Chem Rev. 2004;104(1):293-346.

2. Jimenez-Ruiz A, Perez-Tejeda P, Grueso E, Castillo PM, Prado-Gotor R. Nonfunctionalized gold nanoparticles: synthetic routes and synthesis condition dependence. Chem A Eur J. 2015;21(27):9596-9609. doi:10.1002/chem.20140 5117

3. Gréget R, Nealon GL, Vileno B, et al. Magnetic properties of gold nanoparticles: a room-temperature quantum effect. ChemPhysChem. 2012;13(13):3092-3097. doi:10.1002/cphc.201200394

4. Xu L, Feng L, Dong S, Hao J. Magnetic controlling of migration of DNA and proteins using one-step modified gold nanoparticles. Chem Commun. 2015;51(45):9257-9260. doi:10.1039/c5ec01738f

5. Han G, Ghosh P, Rotello VM. Functionalized gold nanoparticles for drug delivery. Nanomedicine. 2007;2(1):113-123. doi:10.2217/17435889.2.1.113

6. Subramanian P, Meziane D, Wojcieszak R, Dumeignil F, Boukherroub R, Szunerits S. Plasmon-induced electrocatalysis with multi-component nanostructures. Materials (Basel). 2018;12(1):43. doi:10.3390/ma12010043

7. Shpacovitch V, Hergenröder R. Surface plasmon resonance (SPR)-based biosensors as instruments with high versatility and sensitivity. Sensors (Switzerland). 2020;20(11):3010. doi:10.3390/ s20113010

8. Chen YS, Zhao Y, Yoon SJ, Gambhir SS, Emelianov S. Miniature gold nanorods for photoacoustic molecular imaging in the second near-infrared optical window. Nat Nanotechnol. 2019;14 (5):465-472. doi:10.1038/s41565-019-0392-3

9. Jaque D, Martínez Maestro L, Del Rosal B, et al. Nanoparticles for photothermal therapies. Nanoscale. 2014;6(16):9494-9530. doi:10.1039/c4nr00708e

10. Jain PK, ElSayed IH, El-Sayed MA. Au nanoparticles target cancer. Nano Today. 2007;2(1):18-29. doi:10.1016/S17480132(07)70016-6

11. Saha K, Agasti SS, Kim C, Li X, Rotello VM. Gold nanoparticles in chemical and biological sensing. Chem Rev. 2012;112 (5):2739-2779. doi:10.1021/cr2001178

12. Haick H. Chemical sensors based on molecularly modified metallic nanoparticles. J Phys D Appl Phys. 2007;40(23):7173-7186. doi:10.1088/0022-3727/40/23/S01

13. Zeng S, Yong KT, Roy I, Dinh XQ, Yu X, Luan F. A Review on functionalized gold nanoparticles for biosensing applications. Plasmonics. 2011;6(3):491-506. doi:10.1007/s11468-011-9228-1 
14. Deng D, Zhang D, Li Y, Achilefu S, Gu Y. Gold nanoparticles based molecular beacons for in vitro and in vivo detection of the matriptase expression on tumor. Biosens Bioelectron. 2013;49:216-221. doi:10.1016/j.bios.2013.05.018

15. Zhan Y, Yang J, Guo L, et al. Targets regulated formation of boron nitride quantum dots - gold nanoparticles nanocomposites for ultrasensitive detection of acetylcholinesterase activity and its inhibitors. Sensors Actuators B Chem. 2019;279:61-68. doi:10.1016/j.snb.2018.09.097

16. Franco-Ulloa S, Tatulli G, Bore SL, et al. Dispersion state phase diagram of citrate-coated metallic nanoparticles in saline solutions. Nat Commun. 2020;11(1):5422. doi:10.1038/s41467-020-19164-3

17. Fuller M, Köper I. Polyelectrolyte-coated gold nanoparticles: the effect of salt and polyelectrolyte concentration on colloidal stability. Polymers (Basel). 2018;10(12):1336. doi:10.3390/ polym 10121336

18. Hu S, Huang PJJ, Wang J, Liu J. Dissecting the effect of salt for more sensitive label-free colorimetric detection of DNA using gold nanoparticles. Anal Chem. 2020;92(19):13354-13360. doi:10.1021/acs.analchem.0c02688

19. Muangnapoh T, Sano N, Yusa SI, Viriya-empikul N, Charinpanitkul T. Facile strategy for stability control of gold nanoparticles synthesized by aqueous reduction method. Curr Appl Phys. 2010;10(2):708-714. doi:10.1016/j.cap.2009.09.005

20. Goia DV, Matijević E. Tailoring the particle size of monodispersed colloidal gold. Coll Surf A Physicochem Eng Asp. 1999;146(1-3):139-152. doi:10.1016/S0927-7757(98)00790-0

21. Patungwasa W, Hodak JH. pH tunable morphology of the gold nanoparticles produced by citrate reduction. Mater Chem Phys. 2008;108(1):45-54. doi:10.1016/j.matchemphys.2007.09.001

22. Brewer SH, Glomm WR, Johnson MC, Knag MK, Franzen S. Probing BSA binding to citrate-coated gold nanoparticles and surfaces. Langmuir. 2005;21(20):9303-9307. doi:10.1021/la050588t

23. Schubert J, Chanana M. Coating Matters: review on colloidal stability of nanoparticles with biocompatible coatings in biological media, living cells and organisms. Curr Med Chem. 2018;25 (35):4553-4586. doi:10.2174/0929867325666180601101859

24. Moore TL, Rodriguez-Lorenzo L, Hirsch V, et al. Nanoparticle colloidal stability in cell culture media and impact on cellular interactions. Chem Soc Rev. 2015;44 (17):6287-6305. doi:10.1039/c4cs00487f

25. Larson TA, Joshi PP, Sokolov K. Preventing protein adsorption and macrophage uptake of gold nanoparticles via a hydrophobic shield. ACS Nano. 2012;6(10):9182-9190. doi:10.1021/nn3035155

26. Kimling J, Maier M, Okenve B, Kotaidis V, Ballot H, Plech A. Turkevich method for gold nanoparticle synthesis revisited. $J$ Phys Chem B. 2006;110(32):15700-15707. doi:10.1021/jp061667w

27. Sangwan S, Seth R. Synthesis, characterization and stability of gold nanoparticles (AuNPs) in different buffer systems. $J$ Clust Sci. 2021;1-6. doi:10.1007/s10876-020-01956-8

28. Burda C, Chen X, Narayanan R, El-Sayed MA. Chemistry and properties of nanocrystals of different shapes. Chem Rev. 2005;105(4):1025-1102. doi:10.1021/cr030063a

29. Cushing BL, Kolesnichenko VL, O'Connor CJ. Recent advances in the liquid-phase syntheses of inorganic nanoparticles. Chem Rev. 2004;104(9):3893-3946. doi:10.1021/cr030027b

30. Waters CA, Mills AJ, Johnson KA, Schiffrin DJ. Purification of dodecanethiol derivatised gold nanoparticles. Chem Commun. 2003;3(4):540-541. doi:10.1039/b211874b

31. Shah M, Fawcett D, Sharma S, Tripathy SK, Poinern GEJ. Green synthesis of metallic nanoparticles via biological entities. Materials (Basel). 2015;8(11):7278-7308. doi:10.3390/ma8115377

32. Sengani M, Grumezescu AM, Rajeswari VD. Recent trends and methodologies in gold nanoparticle synthesis - a prospective review on drug delivery aspect. OpenNano. 2017;2:37-46. doi:10.1016/j.onano.2017.07.001
33. Hamamoto M, Yagyu H. Two-Phase Brust-Schiffrin Synthesis of Gold Nanoparticles Dispersion in Organic Solvent on Glass Microfluidic Device. IEEE. 2017;632-635. doi:10.1109/ NANO.2017.8117309

34. Turkevich J, Stevenson PC, Hillier J. A study of the nucleation and growth processes in the synthesis of colloidal gold. Discuss Faraday Soc. 1951;11:55-75. doi:10.1039/DF9511100055

35. Amina SJ, Guo B. A review on the synthesis and functionalization of gold nanoparticles as a drug delivery vehicle. Int J Nanomedicine. 2020;15:9823-9857. doi:10.2147/IJN.S279094

36. Brust M, Walker M, Bethell D, Schiffrin DJ, Whyman R. Synthesis of thiol-derivatised gold nanoparticles in a two-phase liquid-liquid system. J Chem Soc Chem Commun. 1994; (7):801-802. doi:10.1039/C39940000801

37. Ward CJ, Tronndorf R, Eustes AS, Auad ML, Davis EW. Seedmediated growth of gold nanorods: limits of length to diameter ratio control. J Nanomater. 2014;2014:1-7. doi:10.1155/2014/765618

38. El-Sayed IH, Huang X, El-Sayed MA. Surface plasmon resonance scattering and absorption of anti-EGFR antibody conjugated gold nanoparticles in cancer diagnostics: applications in oral cancer. Nano Lett. 2005;5(5):829-834. doi:10.1021/n1050074e

39. Edwards EW, Chanana M, Wang D. Capping gold nanoparticles with stimuli-responsive polymers to cross water-oil interfaces: in-depth insight to the trans-interfacial activity of nanoparticles. $J$ Phys Chem C. 2008;112(39):15207-15219. doi:10.1021/jp803840b

40. Nadeem M, Abbasi BH, Younas M, Ahmad W, Khan T. A review of the green syntheses and anti-microbial applications of gold nanoparticles. Green Chem Lett Rev. 2017;10(4):216-227. doi:10.1080/17518253.2017.1349192

41. Jiang K, Wang X, Chuanxi W, Zhang C. On-off-on gold nanocluster-based near infrared fluorescent probe for recognition of $\mathrm{Cu}(\mathrm{II})$ and vitamin C. Microchim Acta. 2017;184:1315-1324. doi:10.1007/s00604-017-2111-9

42. Li D, He Q, Li J. Smart core/shell nanocomposites: intelligent polymers modified gold nanoparticles. Adv Colloid Interface Sci. 2009;149(1-2):28-38. doi:10.1016/j.cis.2008.12.007

43. Du B, Zhao B, Tao P, Yin K, Lei P, Wang Q. Amphiphilic multiblock copolymer stabilized Au nanoparticles. Coll Surf A Physicochem Eng Asp. 2008;317(1-3):194-205. doi:10.1016/j. colsurfa.2007.10.016

44. Scaravelli RCB, Dazzi RL, Giacomelli FC, Machado G, Giacomelli C, Schmidt V. Direct synthesis of coated gold nanoparticles mediated by polymers with amino groups. J Colloid Interface Sci. 2013;397:114-121. doi:10.1016/j. jcis.2013.01.058

45. Shan J, Nuopponen M, Jiang $H$, et al. Amphiphilic gold nanoparticles grafted with poly(N-isopropylacrylamide) and polystyrene. Macromolecules. 2005;38(7):2918-2926. doi:10.1021/ma049269j

46. Nuopponen $\mathrm{M}$, Tenhu H. Gold nanoparticles protected with $\mathrm{pH}$ and temperature-sensitive diblock copolymers. Langmuir. 2007;23(10):5352-5357. doi:10.1021/1a063240m

47. Shan J, Tenhu H. Recent advances in polymer protected gold nanoparticles: synthesis, properties and applications. Chem Commun. 2007;(44):4580-4598. doi:10.1039/b707740h

48. Muddineti OS, Ghosh B, Biswas S. Current trends in using polymer coated gold nanoparticles for cancer therapy. Int J Pharm. 2015;484 (1-2):252-267. doi:10.1016/j.ijpharm.2015.02.038

49. Takara M, Toyoshima M, Seto H, Hoshino Y, Miura Y. Polymermodified gold nanoparticles via RAFT polymerization: a detailed study for a biosensing application. Polym Chem. 2014;5 (3):931-939. doi:10.1039/c3py01001e

50. Kim JH, Lee TR. Thermo- and pH-responsive hydrogel-coated gold nanoparticles. Chem Mater. 2004;16(19):3647-3651. doi:10.1021/cm049764u 
51. Zhu MQ, Wang LQ, Exarhos GJ, Li ADQ. Thermosensitive gold nanoparticles. $J$ Am Chem Soc. 2004;126(9):2656-2657. doi: $10.1021 / \mathrm{ja} 038544 \mathrm{z}$

52. Ehlert S, Taheri SM, Pirner D, Drechsler M, Schmidt HW, Förster S. Polymer ligand exchange to control stabilization and compatibilization of nanocrystals. ACS Nano. 2014;8 (6):6114-6122. doi:10.1021/nn5014512

53. Yuan JJ, Schmid A, Armes SP, Lewis AL. Facile synthesis of highly biocompatible poly(2-(methacryloyloxy)ethyl phosphorylcholine)-coated gold nanoparticles in aqueous solution. Langmuir. 2006;22(26):11022-11027. doi:10.1021/la0616350

54. Klinkova A, Choueiri RM, Kumacheva E. Self-assembled plasmonic nanostructures. Chem Soc Rev. 2014;43(11):3976-3991. doi:10.1039/c3es60341e

55. Li W, Chen X. Gold nanoparticles for photoacoustic imaging. Nanomedicine. 2015;10(2):299-320. doi:10.2217/nnm.14.169

56. Mao Z, Xu H, Wang D. Molecular mimetic self-assembly of colloidal particles. Adv Funct Mater. 2010;20(7):1053-1074. doi:10.1002/adfm.200902076

57. Sukhishvili SA. Responsive polymer films and capsules via layer-by-layer assembly. Curr Opin Colloid Interface Sci. 2005;10(1-2):37-44. doi:10.1016/j.cocis.2005.05.001

58. Qiu Y, Park K. Environment-sensitive hydrogels for drug delivery. Adv Drug Deliv Rev. 2001;53(3):321-339. doi:10.1016/ S0169-409X(01)00203-4

59. Bae Y, Fukushima S, Harada A, Kataoka K. Design of environment-sensitive supramolecular assemblies for intracellular drug delivery: polymeric micelles that are responsive to intracellular pH change. Angew Chemie Int Ed. 2003;42(38):4640-4643. doi:10.1002/anie.200250653

60. Zhang R, Tang M, Bowyer A, Eisenthal R, Hubble J. A novel pHand ionic-strength-sensitive carboxy methyl dextran hydrogel. Biomaterials. 2005;26(22):4677-4683. doi:10.1016/j.biomate rials.2004.11.048

61. Liu R, Zhao X, Wu T, Feng P. Tunable redox-responsive hybrid nanogated ensembles. $J$ Am Chem Soc. 2008;130 (44):14418-14419. doi:10.1021/ja8060886

62. Xia Y, Burke NAD, Stöver HDH. End group effect on the thermal response of narrow-disperse poly(N-isopropylacrylamide) prepared by atom transfer radical polymerization. Macromolecules. 2006;39(6):2275-2283. doi:10.1021/ma0519617

63. Man RWY, Li CH, MacLean MWA, et al. Ultrastable gold nanoparticles modified by bidentate N-heterocyclic carbene ligands. J Am Chem Soc. 2018;140(5):1576-1579. doi:10.1021/jacs.7b08516

64. Raja DA, Musharraf SG, Shah MR, Jabbar A, Bhanger MI, Malik MI. Poly(propylene glycol) stabilized gold nanoparticles: an efficient colorimetric assay for ceftriaxone. J Ind Eng Chem. 2020;87:180-186. doi:10.1016/j.jiec.2020.03.041

65. Subramaniam C, Tom RT, Pradeep T. On the formation of protected gold nanoparticles from $\mathrm{AuCl} 4-\mathrm{By}$ the reduction using aromatic amines. J Nanoparticle Res. 2005;7(2-3):209-217. doi:10.1007/s11051-005-0315-0

66. Salorinne K, Man RWY, Li CH, Taki M, Nambo M, Crudden CM. Water-soluble N-heterocyclic carbene-protected gold nanoparticles: size-controlled synthesis, stability, and optical properties. Angew Chemie Int Ed. 2017;56(22):6198-6202. doi:10.1002/anie.201701605

67. Crudden CM, Horton JH, Narouz MR, et al. Simple direct formation of self-assembled N-heterocyclic carbene monolayers on gold and their application in biosensing. Nat Commun. 2016;7 (1):12654. doi:10.1038/ncomms12654

68. Zhukhovitskiy AV, MacLeod MJ, Johnson JA. Carbene ligands in surface chemistry: from stabilization of discrete elemental allotropes to modification of nanoscale and bulk substrates. Chem Rev. 2015;115 (20):11503-11532. doi:10.1021/acs.chemrev.5b00220
69. Thomas SR, Casini A. N-Heterocyclic carbenes as "smart" gold nanoparticle stabilizers: state-of-the art and perspectives for biomedical applications. J Organomet Chem. 2021;938:121743. doi:10.1016/j.jorganchem.2021.121743

70. Smith CA, Narouz MR, Lummis PA, et al. N-heterocyclic carbenes in materials chemistry. Chem Rev. 2019;119(8):4986-5056. doi:10.1021/acs.chemrev.8b00514

71. MacLeod MJ, Johnson JA. PEGylated N-heterocyclic narbene anchors designed to stabilize gold nanoparticles in biologically relevant media. J Am Chem Soc. 2015;137(25):7974-7977. doi:10.1021/jacs.5b02452

72. Young AJ, Eisen C, Rubio GMDM, Chin JM, Reithofer MR. $\mathrm{pH}$ responsive histidin-2-ylidene stabilized gold nanoparticles. $J \quad$ Inorg Biochem. 2019;199:110707. doi:10.1016/j. jinorgbio.2019.110707

73. MacLeod MJ, Goodman AJ, Ye HZ, Nguyen HVT, Van Voorhis T, Johnson JA. Robust gold nanorods stabilized by bidentate N-heterocyclic-carbene-thiolate ligands. Nat Chem. 2019;11 (1):57-63. doi:10.1038/s41557-018-0159-8

74. Li J, Han J, Xu T, et al. Coating urchinlike gold nanoparticles with polypyrrole thin shells to produce photothermal agents with high stability and photothermal transduction efficiency. Langmuir. 2013;29(23):7102-7110. doi:10.1021/la401366c

75. Tenório-Neto ET, Guilherme MR, Lima-Tenório MK, Rubira AF, Fessi H, Kunita MH. Poly(ethylene glycol)-based hydrogels from preparation methods to applications. J Colloid Sci Biotechnol. 2016;5(1):2-15. doi:10.1166/jcsb.2016.1139

76. Zhang X, Liu B, Servos MR, Liu J. Polarity control for nonthiolated DNA adsorption onto gold nanoparticles. Langmuir. 2013;29(20):6091-6098. doi:10.1021/la400617u

77. Karakoti AS, Das S, Thevuthasan S, Seal S. PEGylated inorganic nanoparticles. Angew Chemie Int Ed. 2011;50(9):1980-1994. doi:10.1002/anie.201002969

78. Manson J, Kumar D, Meenan BJ, Dixon D. Polyethylene glycol functionalized gold nanoparticles: the influence of capping density on stability in various media. Gold Bull. 2011;44(2):99-105. doi:10.1007/s13404-011-0015-8

79. Oh E, Susumu K, Mäkinen AJ, Deschamps JR, Huston AL, Medintz IL. Colloidal stability of gold nanoparticles coated with multithiol- poly(ethylene glycol) ligands: importance of structural constraints of the sulfur anchoring groups. J Phys Chem C. 2013;117(37):18947-18956. doi:10.1021/jp405265u

80. Park G, Seo D, Chung IS, Song H. Poly(ethylene glycol)- and carboxylate-functionalized gold nanoparticles using polymer linkages: single-step synthesis, high stability, and plasmonic detection of proteins. Langmuir. 2013;29(44):13518-13526. doi:10.1021/ la402315a

81. Reznickova A, Slavikova N, Kolska Z, et al. PEGylated gold nanoparticles: stability, cytotoxicity and antibacterial activity. Coll Surf A Physicochem Eng Asp. 2019;560:26-34. doi:10.1016/j.colsurfa.2018.09.083

82. Zou R, Zhang Q, Zhao Q, et al. Thermal stability of gold nanorods in an aqueous solution. Coll Surf A Physicochem Eng Asp. 2010;372(1-3):177-181. doi:10.1016/j.colsurfa.20 10.10 .012

83. Li D, Chi H, Fang WJ. Preparation and thermal stability of oil-based $\mathrm{Au}$ nanofluids. Gaodeng Xuexiao Huaxue Xuebao. 2013;34(2):414-417. doi:10.7503/CJCU20120501

84. Sardar R, Bjorge NS, Shumaker-Parry JS. PH-controlled assemblies of polymeric amine-stabilized gold nanoparticles. Macromolecules. 2008;41(12):4347-4352. doi:10.1021/ma800407s

85. Saha Ray A, Ghann WE, Tsoi PS, et al. Set of Highly stable amine- and carboxylate-terminated dendronized $\mathrm{Au}$ nanoparticles with dense coating and nontoxic mixed-dendronized form. Langmuir. 2019;35 (9):3391-3403. doi:10.1021/acs.langmuir.8b03196 
86. Oh E, Susumu K, Blanco-Canosa JB, Medintz IL, Dawson PE, Mattoussi H. Preparation of stable maleimide-functionalized $\mathrm{Au}$ nanoparticles and their use in counting surface ligands. Small. 2010;6(12):1273-1278. doi:10.1002/smll.201000279

87. Bandulasena MV, Vladisavljević GT, Odunmbaku OG, Benyahia B. Continuous synthesis of PVP stabilized biocompatible gold nanoparticles with a controlled size using a 3D glass capillary microfluidic device. Chem Eng Sci. 2017;171:233-243. doi:10.1016/j.ces.2017.05.035

88. Newman JDS, Blanchard GJ. Formation and encapsulation of gold nanoparticles using a polymeric amine reducing agent. $J$ Nanoparticle Res. 2007;9(5):861-868. doi:10.1007/s11051-006-9145-y

89. Wang L, Yang Q, Cui Y, et al. Highly stable and biocompatible dendrimer-encapsulated gold nanoparticle catalysts for the reduction of 4-nitrophenol. New J Chem. 2017;41(16):8399-8406. doi:10.1039/c7nj01567d

90. Strozyk MS, Chanana M, Pastoriza-Santos I, Pérez-Juste J, LizMarzán LM. Protein/polymer-based dual-responsive gold nanoparticles with $\mathrm{pH}$-dependent thermal sensitivity. Adv Funct Mater. 2012;22(7):1436-1444. doi:10.1002/adfm.201102471

91. Tournebize J, Boudier A, Sapin-Minet A, Maincent P, Leroy P, Schneider R. Role of gold nanoparticles capping density on stability and surface reactivity to design drug delivery platforms. ACS Appl Mater Interfaces. 2012;4(11):5790-5799. doi:10.1021/am3012752

92. Zhou X, El Khoury JM, Qu L, Dai L, Li Q. A facile synthesis of aliphatic thiol surfactant with tunable length as a stabilizer of gold nanoparticles in organic solvents. $J$ Colloid Interface Sci. 2007;308(2):381-384. doi:10.1016/j.jcis.2007.01.040

93. Azubel M, Kornberg RD. Synthesis of water-soluble, thiolate-protected gold nanoparticles uniform in size. Nano Lett. 2016;16(5):3348-3351. doi:10.1021/acs.nanolett.6b00981

94. Zhang F, Zhou Y, Chen Y, Shi Z, Tang Y, Lu T. Facile controlled preparation of phosphonic acid-functionalized gold nanoparticles. $J$ Colloid Interface Sci. 2010;351(2):421-426. doi:10.1016/j. jcis.2010.07.063

95. Mohajeri M, Iranpour P, Vahidi Y, et al. Pegylated deoxycholic acid coated gold nanoparticles as a highly stable CT contrast agent. ChemistrySelect. 2020;5(29):9119-9126. doi:10.1002/ slct.202001634

96. Wang L, Wei G, Sun L, et al. Self-assembly of cinnamic acid-capped gold nanoparticles. Nanotechnology. 2006;17 (12):2907-2912. doi:10.1088/0957-4484/17/12/014

97. Zhang Y, Zhang C, Xu C, et al. Ultrasmall Au nanoclusters for biomedical and biosensing applications: a mini-review. Talanta. 2019;200:432-442. doi:10.1016/j.talanta.2019.03.068

98. Hulkoti NI, Taranath TC. Biosynthesis of nanoparticles using microbes-A review. Coll Surf B Biointerfaces. 2014;121:474-483. doi:10.1016/j.colsurfb.2014.05.027

99. Nasaruddin RR, Chen T, Yao Q, Zang S, Xie J. Toward greener synthesis of gold nanomaterials: from biological to biomimetic synthesis. Coord Chem Rev. 2021;426:213540. doi:10.1016/j. ccr.2020.213540

100. Kong Y, Chen J, Gao F, et al. Near-infrared fluorescent ribonuclease-A-encapsulated gold nanoclusters: preparation, characterization, cancer targeting and imaging. Nanoscale. 2013;5 (3):1009-1017. doi:10.1039/c2nr32760k

101. Xie J, Lee JY, Wang DIC, Ting YP. Silver nanoplates: from biological to biomimetic synthesis. ACS Nano. 2007;1 (5):429-439. doi:10.1021/nn7000883

102. Balasubramanian S, Bezawada SR, Raghavachari D. Green, selective, seedless and one-pot synthesis of triangular Au nanoplates of controlled size using bael gum and mechanistic study. ACS Sustain Chem Eng. 2016;4(7):3830-3839. doi:10.1021/acssuschemeng.6b00596
103. Gonzaga F, Singh S, Brook MA. Biomimetic synthesis of gold nanocrystals using a reducing amphiphile. Small. 2008;4 (9):1390-1398. doi:10.1002/smll.200701163

104. Khan T, Ullah N, Khan MA, Mashwani ZR, Nadhman A. Plantbased gold nanoparticles; a comprehensive review of the decade-long research on synthesis, mechanistic aspects and diverse applications. Adv Colloid Interface Sci. 2019;272:102017. doi:10.1016/j.cis.2019.102017

105. Javed R, Zia M, Naz S, Aisida SO, Ain N, Ao Q. Role of capping agents in the application of nanoparticles in biomedicine and environmental remediation: recent trends and future prospects. J Nanobiotechnology. 2020;18(1):172. doi:10.1186/s12951-02000704-4

106. Satpathy S, Patra A, Ahirwar B, Hussain MD. Process optimization for green synthesis of gold nanoparticles mediated by extract of Hygrophila spinosa T. Anders and their biological applications. Phys E Low Dimensional Syst Nanostruct. 2020;121:113830. doi:10.1016/j.physe.2019.113830

107. Lee J, Kim HY, Zhou H, et al. Green synthesis of phytochemical-stabilized Au nanoparticles under ambient conditions and their biocompatibility and antioxidative activity. J Mater Chem. 2011;21(35):13316-13326. doi:10.1039/c1jm11592h

108. Ankamwar B, Pansare S, Sur UK. Centrifuge controlled shape tuning of biosynthesized gold nanoparticles obtained from Plumbago zeylanica leaf extract. $J$ Nanosci Nanotechnol. 2017;17(2):1041-1045. doi:10.1166/jnn.2017.12662

109. Singh R, Nawale L, Arkile M, et al. Phytogenic silver, gold, and bimetallic nanoparticles as novel antitubercular agents. Int J Nanomedicine. 2016;11:1889-1897. doi:10.2147/IJN.S102488

110. Salunke GR, Ghosh S, Santosh Kumar RJ, et al. Rapid efficient synthesis and characterization of silver, gold, and bimetallic nanoparticles from the medicinal plant Plumbago zeylanica and their application in biofilm control. Int J Nanomedicine. 2014;9 (1):2635-2653. doi:10.2147/IJN.S59834

111. Ghosh S, Patil S, Ahire M, et al. Synthesis of silver nanoparticles using Dioscorea bulbifera tuber extract and evaluation of its synergistic potential in combination with antimicrobial agents. Int J Nanomedicine. 2012;7:483. doi:10.2147/ijn.s24793

112. Ghosh S, Gurav SP, Harke AN, et al. Dioscorea oppositifolia mediated synthesis of gold and silver nanoparticles with catalytic activity. J Nanomed Nanotechnol. 2016;07(05):2. doi:10.4172/21577439.1000398

113. Ghosh S, Patil S, Ahire M, et al. Synthesis of Gold Nanoanisotrops Using Dioscorea bulbifera Tuber Extract. J Nanomater. 2011;2011:1-8. doi:10.1155/2011/354793

114. Engelbrekt C, Sørensen KH, Zhang J, Welinder AC, Jensen PS, Ulstrup J. Green synthesis of gold nanoparticles with starch-glucose and application in bioelectrochemistry. $J$ Mater Chem. 2009;19(42):7839-7847. doi:10.1039/b911111e

115. Parveen R, Ullah S, Sgarbi R, Tremiliosi-Filho G. One-pot ligand-free synthesis of gold nanoparticles: the role of glycerol as reducing-cum-stabilizing agent. Coll Surf A Physicochem Eng Asp. 2019;565:162-171. doi:10.1016/j.colsurfa.2019.01.005

116. Farag RS, El-Baroty GS, Basuny AM. Safety evaluation of olive phenolic compounds as natural antioxidants. Int J Food Sci Nutr. 2003;54(3):159-174. doi:10.1080/0963748031000136306

117. Khalil MMH, Ismail EH, El-Magdoub F. Biosynthesis of $\mathrm{Au}$ nanoparticles using olive leaf extract. 1st Nano Updates. Arab J Chem. 2012;5(4):431-437. doi:10.1016/j.arabjc.2010.11.011

118. Ling LT, Yap SA, Radhakrishnan AK, Subramaniam T, Cheng HM, Palanisamy UD. Standardised Mangifera indica extract is an ideal antioxidant. Food Chem. 2009;113 (4):1154-1159. doi:10.1016/j.foodchem.2008.09.004 
119. Philip D. Rapid green synthesis of spherical gold nanoparticles using Mangifera indica leaf. Spectrochim Acta - Part A Mol Biomol Spectrosc. 2010;77(4):807-810. doi:10.1016/j. saa.2010.08.008

120. Huang X, Wu H, Liao X, Shi B. One-step, size-controlled synthesis of gold nanoparticles at room temperature using plant tannin. Green Chem. 2010;12(3):395. doi:10.1039/b918176h

121. Djajadisastra J, Sutriyo PP, Pujiyanto A. Antioxidant activity of gold nanoparticles using gum arabic as a stabilizing agent. Int J Pharm Pharm Sci. 2014;6(7):462-465.

122. García I, Sánchez-Iglesias A, Henriksen-Lacey M, Grzelczak M, Penadés S, Liz-Marzán LM. Glycans as biofunctional ligands for gold nanorods: stability and targeting in protein-rich media. $J$ Am Chem Soc. 2015;137(10):3686-3692. doi:10.1021/jacs.5b01001

123. Dumur F, Guerlin A, Dumas E, Bertin D, Gigmes D, Mayer CR. Controlled spontaneous generation of gold nanoparticles assisted by dual reducing and capping agents. Gold Bull. 2011;44 (2):119-137. doi:10.1007/s13404-011-0018-5

124. Lee KX, Shameli K, Yew YP, et al. Recent developments in the facile bio-synthesis of gold nanoparticles (AuNPs) and their biomedical applications. Int $J$ Nanomedicine. 2020;15:275-300. doi:10.2147/IJN.S233789

125. Patil MP, Kim GD. Marine microorganisms for synthesis of metallic nanoparticles and their biomedical applications. Coll Surf B Biointerfaces. 2018;172:487-495. doi:10.1016/j. colsurfb.2018.09.007

126. Kitching M, Ramani M, Marsili E. Fungal biosynthesis of gold nanoparticles: mechanism and scale up. Microb Biotechnol. 2015;8(6):904-917. doi:10.1111/1751-7915.12151

127. Dhillon GS, Brar SK, Kaur S, Verma M. Green approach for nanoparticle biosynthesis by fungi: current trends and applications. Crit Rev Biotechnol. 2012;32(1):49-73. doi:10.3109/07388551.2010.550568

128. Qu Y, Pei X, Shen W, et al. Biosynthesis of gold nanoparticles by Aspergillum $s p$. WL-Au for degradation of aromatic pollutants. Phys E Low Dimensional Syst Nanostruct. 2017;88:133-141. doi:10.1016/j.physe.2017.01.010

129. Eskandari-Nojedehi M, Jafarizadeh-Malmiri H, RahbarShahrouzi J. Hydrothermal green synthesis of gold nanoparticles using mushroom (Agaricus bisporus) extract: physico-chemical characteristics and antifungal activity studies. Green Process Synth. 2018;7(1):38-47. doi:10.1515/gps-2017-0004

130. Thirumurugan A, Ramachandran S, Tomy NA, Jiflin GJ, Rajagomathi G. Biological synthesis of gold nanoparticles by Bacillus subtilis and evaluation of increased antimicrobial activity against clinical isolates. Korean $J$ Chem Eng. 2012;29 (12):1761-1765. doi:10.1007/s11814-012-0055-7

131. Kalabegishvili T, Murusidze I, Kirkesali E, et al. Gold and silver nanoparticles in Spirulina platensis biomass for medical application. Ecol Chem Eng S. 2013;20(4):621-631. doi:10.2478/eces-2013-0043

132. Tebbe M, Kuttner C, Männel M, Fery A, Chanana M. Colloidally stable and surfactant-free protein-coated gold nanorods in biological media. ACS Appl Mater Interfaces. 2015;7(10):5984-5991. doi:10.1021/acsami.5b00335

133. Liu N, Liedl T. DNA-assembled advanced plasmonic architectures. Chem Rev. 2018;118(6):3032-3053. doi:10.1021/ acs.chemrev. $7 \mathrm{~b} 00225$

134. Shin J, Zhang X, Liu J. DNA-functionalized gold nanoparticles in macromolecularly crowded polymer solutions. J Phys Chem B. 2012;116(45):13396-13402. doi:10.1021/jp310662m

135. Wang CC, Wu SM, Li HW, Chang HT. Biomedical applications of DNA-conjugated gold nanoparticles. ChemBioChem. 2016;17 (12):1052-1062. doi:10.1002/cbic.201600014
136. Kang H, Buchman JT, Rodriguez RS, et al. Stabilization of silver and gold nanoparticles: preservation and improvement of plasmonic functionalities. Chem Rev. 2019;119(1):664-699. doi:10.1021/ acs.chemrev.8b00341

137. Nguyen DT, Kim DJ, Kim KS. Controlled synthesis and biomolecular probe application of gold nanoparticles. Micron. 2011;42 (3):207-227. doi:10.1016/j.micron.2010.09.008

138. Aryal S, Remant BKC, Dharmaraj N, Bhattarai N, Kim CH, Kim HY. Spectroscopic identification of SAu interaction in cysteine capped gold nanoparticles. Spectrochim Acta - Part A Mol Biomol Spectrosc. 2006;63(1):160-163. doi:10.1016/j. saa.2005.04.048

139. Kumar S, Jha I, Mogha NK, Venkatesu P. Biocompatibility of surface-modified gold nanoparticles towards red blood cells and haemoglobin. Appl Surf Sci. 2020;512:145573. doi:10.1016/j. apsusc.2020.145573

140. Cheung-Lau JC, Liu D, Pulsipher KW, Liu W, Dmochowski IJ. Engineering a well-ordered, functional protein-gold nanoparticle assembly. J Inorg Biochem. 2014;130(1):59-68. doi:10.1016/j. jinorgbio.2013.10.003

141. Thilagam R, Gnanamani A. Preparation, characterization and stability assessment of keratin and albumin functionalized gold nanoparticles for biomedical applications. Appl Nanosci. 2020;10 (6):1879-1892. doi:10.1007/s13204-020-01250-z

142. Lee HE, Ahn HY, Mun J, et al. Amino-acid- and peptide-directed synthesis of chiral plasmonic gold nanoparticles. Nature. 2018;556(7701):360-364. doi:10.1038/s41586-018-0034-1

143. Kitching M, Choudhary P, Inguva S, et al. Fungal surface protein mediated one-pot synthesis of stable and hemocompatible gold nanoparticles. Enzyme Microb Technol. 2016;95:76-84. doi:10.1016/j.enzmictec.2016.08.007

144. Love JC, Estroff LA, Kriebel JK, Nuzzo RG, Whitesides GM. Selfassembled monolayers of thiolates on metals as a form of nanotechnology. Chem Rev. 2005;105(4):1103-1169. doi:10.1021/ cr0300789

145. Guo S, Wang E. Synthesis and electrochemical applications of gold nanoparticles. Anal Chim Acta. 2007;598(2):181-192. doi:10.1016/j.aca.2007.07.054

146. Liu B, Liu J. Interface-driven hybrid materials based on DNA-functionalized gold nanoparticles. Matter. 2019;1 (4):825-847. doi:10.1016/j.matt.2019.08.008

147. Nam JM, Thaxton CS, Mirkin CA. Nanoparticle-based bio-bar codes for the ultrasensitive detection of proteins. Science (80-). 2003;301(5641):1884-1886. doi:10.1126/ science. 1088755

148. Elghanian R, Storhoff JJ, Mucic RC, Letsinger RL, Mirkin CA. Selective colorimetric detection of polynucleotides based on the distance-dependent optical properties of gold nanoparticles. Science (80-). 1997;277(5329):1078-1081. doi:10.1126/science.277.5329.1078

149. Zhou W, Saran R, Liu J. Metal sensing by DNA. Chem Rev. 2017;117(12):8272-8325. doi:10.1021/acs.chemrev.7b00063

150. Zhang X, Servos MR, Liu J. Surface science of DNA adsorption onto citrate-capped gold nanoparticles. Langmuir. 2012;28 (8):3896-3902. doi:10.1021/la205036p

151. Hwu S, Garzuel M, Forró C, et al. An analytical method to control the surface density and stability of DNA-gold nanoparticles for an optimized biosensor. Coll Surf B Biointerfaces. 2020;187:110650. doi:10.1016/j.colsurfb.2019.110650

152. Hinman SS, McKeating KS, Cheng Q. DNA linkers and diluents for ultrastable gold nanoparticle bioconjugates in multiplexed assay development. Anal Chem. 2017;89(7):4272-4279. doi:10.1021/acs.analchem.7b00341

153. Ma X, Guo Z, Mao Z, Tang Y, Miao P. Colorimetric theophylline aggregation assay using an RNA aptamer and non-crosslinking gold nanoparticles. Microchim Acta. 2018;185(1):33. doi:10.1007/s00604-017-2606-4 
154. Shah SS, Cultrara CN, Ramos JA, Samuni U, Zilberberg J, Sabatino D. Bifunctional Au-templated RNA nanoparticles enable direct cell uptake detection and GRP75 knockdown in prostate cancer. J Mater Chem B. 2020;8(10):2169-2176. doi:10.1039/c9tb02438g

155. Jin R. Atomically precise metal nanoclusters: stable sizes and optical properties. Nanoscale. 2015;7(5):1549-1565. doi:10.1039/c4nr05794e

156. Jin R, Zeng C, Zhou M, Chen Y. Atomically precise colloidal metal nanoclusters and nanoparticles: fundamentals and opportunities. Chem Rev. 2016;116(18):10346-10413. doi:10.1021/acs.chemrev.5b00703

157. Chakraborty I, Pradeep T. Atomically precise clusters of noble metals: emerging link between atoms and nanoparticles. Chem Rev. 2017;117(12):8208-8271. doi:10.1021/acs.chemrev.6b00769

158. Xiao Y, Wu Z, Yao Q, Xie J. Luminescent metal nanoclusters: biosensing strategies and bioimaging applications. Aggregate. 2021;2(1):114-132. doi:10.1002/agt2.11

159. Kang X, Zhu M. Tailoring the photoluminescence of atomically precise nanoclusters. Chem Soc Rev. 2019;48(8):2422-2457. doi: $10.1039 / \mathrm{c} 8 \mathrm{cs} 00800 \mathrm{k}$

160. Zhu M, Aikens CM, Hendrich MP, et al. Reversible switching of magnetism in thiolate-protected Au 25 superatoms. $\mathrm{J} \mathrm{Am} \mathrm{Chem}$ Soc. 2009;131(7):2490-2492. doi:10.1021/ja809157f

161. Dainese T, Antonello S, Gascón JA, et al. $\mathrm{Au}_{25(\mathrm{SEt}) 18}$, a nearly naked thiolate-protected $\mathrm{Au}_{25}$ cluster: structural analysis by single crystal $\mathrm{X}$-ray crystallography and electron nuclear double resonance. $A C S$ Nano. 2014;8(4):3904-3912. doi:10.1021/nn500805n

162. Nie L, Xiao X, Yang H. Preparation and biomedical applications of gold nanocluster. J Nanosci Nanotechnol. 2016;16 (8):8164-8175. doi:10.1166/jnn.2016.12373

163. Compel WS, Wong OA, Chen $\mathrm{X}$, et al. Dynamic diglyme-mediated self-assembly of gold nanoclusters. ACS Nano. 2015;9(12):11690-11698. doi:10.1021/acsnano.5b02850

164. Tero T-R, Malola S, Koncz B, et al. Dynamic stabilization of the ligand-metal interface in atomically precise gold nanoclusters $\mathrm{Au}_{68}$ and $\mathrm{Au}_{144}$ protected by meta-mercaptobenzoic acid. ACS Nano. 2017;11(12):11872-11879. doi:10.1021/ acsnano. $7 \mathrm{~b} 07787$

165. Dreier TA, Andrea Wong O, Ackerson CJ. Oxidative decomposition of Au25(SR)18 clusters in a catalytic context. Chem Commun. 2015;51(7):1240-1243. doi:10.1039/c4cc07832b

166. Yan L, Yu Y, Xia Z. Microwave-assisted in situ synthesis of fluorescent gold nanoclusters with BSA/montmorillonite and application on latent fingermark imaging. Sci China Chem. 2018;61(5):619-626. doi:10.1007/s11426-017-9216-7

167. Jao YC, Chen MK, Lin SY. Enhanced quantum yield of dendrimer-entrapped gold nanodots by a specific ion-pair association and microwave irradiation for bioimaging. Chem Commun. 2010;46(15):2626-2628. doi:10.1039/b926364k

168. Yuan X, Luo Z, Zhang Q, et al. Synthesis of highly fluorescent metal $(\mathrm{Ag}, \mathrm{Au}, \mathrm{Pt}$, and $\mathrm{Cu}$ ) nanoclusters by electrostatically induced reversible phase transfer. ACS Nano. 2011;5 (11):8800-8808. doi:10.1021/nn202860s

169. Sokołowska K, Malola S, Lahtinen M, et al. Towards controlled synthesis of water-soluble gold nanoclusters: synthesis and analysis. J Phys Chem C. 2019;123(4):2602-2612. doi:10.1021/ acs.jpcc. $8 \mathrm{~b} 11056$

170. Joseph D, Geckeler KE. Synthesis of highly fluorescent gold nanoclusters using egg white proteins. Coll Surf B Biointerfaces. 2014;115:46-50. doi:10.1016/j.colsurfb.2013.11.017

171. Liu C, Lin J, Shi Y, Li G. Efficient synthesis of $\mathrm{Au}_{99(\mathrm{SR}) 42}$ nanoclusters. Nanoscale. 2015;7(14):5987-5990. doi:10.1039/ C5NR00543D

172. Pettibone JM, Hudgens JW. Gold cluster formation with phosphine ligands: etching as a size-selective synthetic pathway for small clusters? ACS Nano. 2011;5(4):2989-3002. doi:10.1021/nn200053b
173. Shang L, Azadfar N, Stockmar F, et al. One-pot synthesis of near-infrared fluorescent gold clusters for cellular fluorescence lifetime imaging. Small. 2011;7(18):2614-2620. doi:10.1002/ smll.201100746

174. Tao Y, Li Z, Ju E, Ren J, Qu X. Polycations-functionalized water-soluble gold nanoclusters: a potential platform for simultaneous enhanced gene delivery and cell imaging. Nanoscale. 2013;5(13):6154-6160. doi:10.1039/C3NR01326J

175. Bao J, Yang L, Huang T, et al. XAFS study on thiol etching of diphosphine-stabilized gold nanoclusters. Radiat Phys Chem. 2017;137:99-103. doi:10.1016/j.radphyschem.2016.01.027

176. Chen TH, Yu CJ, Tseng WL. Sinapinic acid-directed synthesis of gold nanoclusters and their application to quantitative matrix-assisted laser desorption/ionization mass spectrometry. Nanoscale. 2014;6 (3):1347-1353. doi:10.1039/C3NR04991D

177. Guan ZJ, Hu F, Li JJ, Wen ZR, Lin YM, Wang QM. Isomerization in alkynyl-protected gold nanoclusters. $J \mathrm{Am}$ Chem Soc. 2020;142(6):2995-3001. doi:10.1021/jacs.9b11836

178. Narouz MR, Osten KM, Unsworth PJ, et al. N-heterocyclic carbene-functionalized magic-number gold nanoclusters. Nat Chem. 2019;11(5):419-425. doi:10.1038/s41557-019-0246-5

179. Liu Z, Wu Z, Yao Q, Cao Y, Chai OJH, Xie J. Correlations between the fundamentals and applications of ultrasmall metal nanoclusters: recent advances in catalysis and biomedical applications. Nano Today. 2021;36:101053. doi:10.1016/j.nantod.2020.101053

180. Li Q, Pan Y, Chen T, et al. Design and mechanistic study of a novel gold nanocluster-based drug delivery system. Nanoscale. 2018;10(21):10166-10172. doi:10.1039/c8nr02189a

181. Jiang X, Sun Y, Shang L, Yang C, Kong L, Zhang Z. Green tea extract-assembled nanoclusters for combinational photothermal and chemotherapy. J Mater Chem B. 2019;7(39):5972-5982. doi:10.1039/c9tb01546a

182. Goswami U, Sahoo AK, Chattopadhyay A, Ghosh SS. In situ synthesis of luminescent Au nanoclusters on a bacterial template for rapid detection, quantification, and distinction of kanamycin-resistant bacteria. ACS Omega. 2018;3 (6):6113-6119. doi:10.1021/acsomega.8b00504

183. Balasubramanian SK, Yang L, Yung LYL, Ong CN, Ong WY, $\mathrm{Yu}$ LE. Characterization, purification, and stability of gold nanoparticles. Biomaterials. 2010;31(34):9023-9030. doi:10.1016/j.biomaterials.2010.08.012

184. Zhang X, Servos MR, Liu J. Ultrahigh nanoparticle stability against salt, $\mathrm{pH}$, and solvent with retained surface accessibility via depletion stabilization. $J$ Am Chem Soc. 2012;134 (24):9910-9913. doi:10.1021/ja303787e

185. Oh E, Susumu K, Goswami R, Mattoussi H. One-phase synthesis of water-soluble gold nanoparticles with control over size and surface functionalities. Langmuir. 2010;26(10):7604-7613. doi: $10.1021 / 1 \mathrm{a} 904438 \mathrm{~s}$

186. Sztandera K, Gorzkiewicz M, Klajnert-Maculewicz B. Gold nanoparticles in cancer treatment. Mol Pharm. 2019;16(1):1-23. doi:10.1021/acs.molpharmaceut.8b00810

187. Boisselier E, Astruc D. Gold nanoparticles in nanomedicine: preparations, imaging, diagnostics, therapies and toxicity. Chem Soc Rev. 2009;38(6):1759-1782. doi:10.1039/b806051g

188. Jeong HH, Choi E, Ellis E, Lee TC. Recent advances in gold nanoparticles for biomedical applications: from hybrid structures to multi-functionality. J Mater Chem B. 2019;7(22):3480-3496. doi:10.1039/c9tb00557a

189. Balfourier A, Kolosnjaj-Tabi J, Luciani N, Carn F, Gazeau F, Murphy CJ. Gold-based therapy: from past to present. Proc Natl Acad Sci USA. 2020;117(37):22639-22648. doi:10.1073/pnas.2007285117

190. Qiao Z, Zhang J, Hai X, Yan Y, Song W, Bi S. Recent advances in templated synthesis of metal nanoclusters and their applications in biosensing, bioimaging and theranostics. Biosens Bioelectron. 2021;176:112898. doi:10.1016/j.bios.2020.112898 
191. Zhao N, Yan L, Zhao X, et al. Versatile types of organic/inorganic nanohybrids: from strategic design to biomedical applications. Chem Rev. 2018;119(3):1666-1762. doi:10.1021/acs.chemrev.8b00401

192. Qiu L, Chen T, Öçsoy I, et al. A cell-targeted, size-photocontrollable, nuclear-uptake nanodrug delivery system for drug-resistant cancer therapy. Nano Lett. 2015;15(1):457-463. doi:10.1021/nl503777s

193. Chen YH, Tsai CY, Huang PY, et al. Methotrexate conjugated to gold nanoparticles inhibits tumor growth in a syngeneic lung tumor model. Mol Pharm. 2007;4(5):713-722. doi:10.1021/mp060132k

194. Sulaiman GM, Waheeb HM, Jabir MS, Khazaal SH, Dewir YH, Naidoo Y. Hesperidin loaded on gold nanoparticles as a drug delivery system for a successful biocompatible, anti-Cancer, anti-inflammatory and phagocytosis inducer model. Sci Rep. 2020;10(1):9362. doi:10.1038/s41598-020-66419-6

195. Liu Y, Luo J, Chen X, Liu W, Chen T. Cell membrane coating technology: a promising strategy for biomedical applications. Nano Micro Lett. 2019;11(1):100. doi:10.1007/s40820-019-0330-9

196. Peng C, Xu J, Yu M, et al. Tuning the in vivo transport of anticancer drugs using renal-clearable gold nanoparticles. Angew Chemie Int Ed. 2019;58(25):8479-8483. doi:10.1002/anie.201903256

197. Sun H, Su J, Meng Q, et al. Cancer cell membrane-coated gold nanocages with hyperthermia-triggered drug release and homotypic target inhibit growth and metastasis of breast cancer. $A d v$ Funct Mater. 2017;27(3):1604300. doi:10.1002/adfm.201604300

198. Kwon Y, Choi Y, Jang J, Yoon S, Choi J. Nir laser-responsive pnipam and gold nanorod composites for the engineering of thermally reactive drug delivery nanomedicine. Pharmaceutics. 2020;12(3):204. doi:10.3390/pharmaceutics12030204

199. Wang X, Jin N, Wang Q, et al. MiRNA delivery system based on stimuli-responsive gold nanoparticle aggregates for multimodal tumor therapy. ACS Appl Bio Mater. 2019;2(7):2833-2839. doi:10.1021/acsabm.9b00240

200. Ding $\mathrm{Y}, \mathrm{Xu} \mathrm{H}, \mathrm{Xu} \mathrm{C}$, et al. A nanomedicine fabricated from gold nanoparticles-decorated metal-organic framework for cascade chemo/chemodynamic ccancer therapy. Adv Sci. 2020;7 (17):2001060. doi:10.1002/advs.202001060

201. Smith BR, Gambhir SS. Nanomaterials for in vivo imaging. Chem Rev. 2017;117(3):901-986. doi:10.1021/acs.chemrev.6b00073

202. Hester SC, Kuriakose M, Nguyen CD, Mallidi S. Role of ultrasound and photoacoustic imaging in photodynamic therapy for cancer. Photochem Photobiol. 2020;96(2):260-279. doi:10.1111/php.13217

203. Lusic H, Grinstaff MW. X-ray-computed tomography contrast agents. Chem Rev. 2013;113(3):1641-1666. doi:10.1021/cr200358s

204. Alric C, Taleb J, Le Duc G, et al. Gadolinium chelate coated gold nanoparticles as contrast agents for both X-ray computed tomography and magnetic resonance imaging. $\mathrm{J}$ Am Chem Soc. 2008;130(18):5908-5915. doi:10.1021/ja078176p

205. Kiessling F, Pichler BJ. Small Animal Imaging: Basics and Practical Guide. Springer Science \& Business Media; 2011. doi:10.1007/978-3-642-12945-2

206. Kim D, Park S, Jae HL, Yong YJ, Jon S. Antibiofouling polymer-coated gold nanoparticles as a contrast agent for in vivo X-ray computed tomography imaging. $\mathrm{J}$ Am Chem Soc. 2007;129(24):7661-7665. doi:10.1021/ja071471p

207. Cole LE, Ross RD, Tilley JM, Vargo-Gogola T, Roeder RK. Gold nanoparticles as contrast agents in X-ray imaging and computed tomography. Nanomedicine. 2015;10(2):321-341. doi:10.2217/ nnm.14.171

208. Cai QY, Kim SH, Choi KS, et al. Colloidal gold nanoparticles as a blood-pool contrast agent for x-ray computed tomography in mice. Invest Radiol. 2007;42(12):797-806. doi:10.1097/ RLI.0b013e31811ecdcd

209. Zhang Z, Ross RD, Roeder RK. Preparation of functionalized gold nanoparticles as a targeted X-ray contrast agent for damaged bone tissue. Nanoscale. 2010;2(4):582-586. doi:10.1039/ b9nr00317g
210. Iranpour $\mathrm{P}$, Ajamian $\mathrm{M}$, Safavi A, Iranpoor $\mathrm{N}$, Abbaspour A, Javanmardi S. Synthesis of highly stable and biocompatible gold nanoparticles for use as a new X-ray contrast agent. $J$ Mater Sci Mater Med. 2018;29(5):48. doi:10.1007/s10856-018-6053-5

211. Wang LV, Hu S. Photoacoustic tomography: in vivo imaging from organelles to organs. Science. 2012;335(6075):1458-1462. doi:10.1126/science. 1216210

212. Li C, Chen T, Ocsoy I, et al. Gold-coated $\mathrm{Fe}_{3} \mathrm{O}_{4}$ nanoroses with five unique functions for cancer cell targeting, imaging, and therapy. Adv Funct Mater. 2014;24(12):1772-1780. doi:10.1002/ adfm.201301659

213. Zhang Q, Iwakuma N, Sharma P, et al. Gold nanoparticles as a contrast agent for invivo tumor imaging with photoacoustic tomography. Nanotechnology. 2009;20(39):395102. doi:10.1088/ 0957-4484/20/39/395102

214. Song $X, Z$ hu $W$, Ge $X$, et al. A new class of NIR-II gold nanocluster-based protein biolabels for in vivo tumor-targeted imaging. Angew Chemie Int Ed. 2021;60(3):1306-1312. doi:10.1002/anie. 202010870

215. Liu H, Hong G, Luo Z, et al. Atomic-precision gold clusters for NIR-II imaging. Adv Mater. 2019;31(46):1901015. doi:10.1002/ adma.201901015

216. Wu M, Li Z, Yao J, Shao Z, Chen X. Pea protein/gold nanocluster/ indocyanine green ternary hybrid for near-infrared fluorescence/computed tomography dual-modal imaging and synergistic photodynamic/ photothermal therapy. ACS Biomater Sci Eng. 2019;5(9):4799-4807. doi:10.1021/acsbiomaterials.9b00794

217. Masters A, Bown SG. Interstitial laser hyperthermia. Semin Surg Oncol. 1992;8(4):242-249. doi:10.1002/ssu.2980080410

218. Depciuch J, Stec M, Kandler M, Baran J, Parlinska-Wojtan M. From spherical to bone-shaped gold nanoparticles-Time factor in the formation of $\mathrm{Au} \mathrm{NPs,} \mathrm{their} \mathrm{optical} \mathrm{and} \mathrm{photothermal}$ properties. Photodiagnosis Photodyn Ther. 2020;30:101670. doi:10.1016/j.pdpdt.2020.101670

219. Von Maltzahn G, Park JH, Agrawal A, et al. Computationally guided photothermal tumor therapy using long-circulating gold nanorod antennas. Cancer Res. 2009;69(9):3892-3900. doi:10.1158/0008-5472.CAN-08-4242

220. Lin M, Guo C, Li J, et al. Polypyrrole-coated chainlike gold nanoparticle architectures with the $808 \mathrm{~nm}$ photothermal transduction efficiency up to 70\%. ACS Appl Mater Interfaces. 2014;6 (8):5860-5868. doi:10.1021/am500715f

221. Yang Y, Chen M, Wu Y, et al. Ultrasound assisted one-step synthesis of Au@Pt dendritic nanoparticles with enhanced NIR absorption for photothermal cancer therapy. RSC Adv. 2019;9 (49):28541-28547. doi:10.1039/c9ra04286e

222. Zeng J, Yang W, Shi D, Li X, Zhang H, Chen M. Porphyrin derivative conjugated with gold nanoparticles for dual-modality photodynamic and photothermal therapies in vitro. ACS Biomater Sci Eng. 2018;4 (3):963-972. doi:10.1021/acsbiomaterials.7b00886

223. Mirkin CA, Letsinger RL, Mucic RC, Storhoff JJ. A DNA-based method for rationally assembling nanoparticles into macroscopic materials. Nature. 1996;382(6592):607-609. doi:10.1038/ $382607 \mathrm{a} 0$

224. Baptista P, Pereira E, Eaton P, et al. Gold nanoparticles for the development of clinical diagnosis methods. Anal Bioanal Chem. 2008;391(3):943-950. doi:10.1007/s00216-007-1768-z

225. Li H, Rothberg L. Colorimetric detection of DNA sequences based on electrostatic interactions with unmodified gold nanoparticles. Proc Natl Acad Sci $U$ S A. 2004;101 (39):14036-14039. doi:10.1073/pnas.0406115101

226. Azzazy HME, Mansour MMH, Samir TM, Franco R. Gold nanoparticles in the clinical laboratory: principles of preparation and applications. Clin Chem Lab Med. 2012;50(2):193-209. doi:10.1515/cclm.2011.732 
227. Bowey K, Tanguay J-F, Sandros MG, Tabrizian M. Microwaveassisted synthesis of surface-enhanced Raman scattering nanoprobes for cellular sensing. Coll Surf $B$ Biointerfaces. 2014;122:617-622. doi:10.1016/j.colsurfb.2014.07.040

228. Yu S, Zhou Y, Sun Y, et al. Endogenous mRNA triggered DNA-Au nanomachine for in situ imaging and targeted multimodal synergistic cancer therapy. Angew Chemie Int Ed. 2021;60 (11):5948-5958. doi:10.1002/anie.202012801

229. Nietzold C, Lisdat F. Fast protein detection using absorption properties of gold nanoparticles. Analyst. 2012;137 (12):2821-2826. doi:10.1039/c2an35054h

230. Shukoor MI, Altman MO, Han D, et al. Aptamer-nanoparticle assembly for logic-based detection. ACS Appl Mater Interfaces. 2012;4(6):3007-3011. doi:10.1021/am300374q

231. Eissa S, Shawky SM, Matboli M, Mohamed S, Azzazy HME. Direct detection of unamplified hepatoma upregulated protein RNA in urine using gold nanoparticles for bladder cancer diagnosis. Clin Biochem. 2014;47(1-2):104-110. doi:10.1016/j. clinbiochem.2013.10.022

232. Wu J, Li W, Hajisalem G, et al. Trace cancer biomarker quantification using polystyrene-functionalized gold nanorods. Biomed Opt Express. 2014;5(12):4101. doi:10.1364/boe.5.004101

233. Wang J, Wuethrich A, Sina AAI, et al. Tracking extracellular vesicle phenotypic changes enables treatment monitoring in melanoma. Sci $A d v$. 2020;6(9):eaax3223. doi:10.1126/sciadv.aax3223

234. Kurdekar AD, Chunduri LAA, Manohar CS, Haleyurgirisetty MK, Hewlett IK, Venkataramaniah K Streptavidin-conjugated gold nanoclusters as ultrasensitive fluorescent sensors for early diagnosis of HIV infection. Sci $A d v$. 2018;4(11):eaar6280. doi:10.1126/sciadv.aar6280

235. Zhang Y, Li S, Liu H, Long W, Zhang XD. Enzyme-like properties of gold clusters for biomedical application. Front Chem. 2020;8:219. doi:10.3389/fchem.2020.00219

236. Wang GL, Jin LY, Dong YM, Wu XM, Li ZJ. Intrinsic enzyme mimicking activity of gold nanoclusters upon visible light triggering and its application for colorimetric trypsin detection. Biosens Bioelectron. 2015;64:523-529. doi:10.1016/j.bios.2014.09.071

237. Liu R, Cheng D, Zhou Q, Niu F, Hu K. Gold nanoclusters perform enzyme-like photocatalysis for prodrug activation. ACS Appl Nano Mater. 2021;4(2):990-994. doi:10.1021/acsanm.1c00014

238. Liu CP, Wu TH, Liu CY, et al. Self-supplying $\mathrm{O}_{2}$ through the catalase-like activity of gold nanoclusters for photodynamic therapy against hypoxic cancer cells. Small. 2017;13(26):1700278. doi:10.1002/smll.201700278

239. Zhang Y, Song P, Chen T, et al. Unique size-dependent nanocatalysis revealed at the single atomically precise gold cluster level. Proc Natl Acad Sci USA. 2018;115(42):10588-10593. doi:10.1073/pnas.1805711115

240. Liu H, Li Y, Sun S, et al. Catalytically potent and selective clusterzymes for modulation of neuroinflammation through single-atom substitutions. Nat Commun. 2021;12(1):114. doi:10.1038/s41467-020-20275-0

241. Sun S, Liu H, Xin Q, et al. Atomic engineering of clusterzyme for relieving acute neuroinflammation through lattice expansion. Nano Lett. 2021;21(6):2562-2571. doi:10.1021/acs.nanolett.0c05148

242. Zheng K, Setyawati MI, Leong DT, Xie J. Surface ligand chemistry of gold nanoclusters determines their antimicrobial ability. Chem Mater. 2018;30(8):2800-2808. doi:10.1021/acs.chemmater.8b00667
243. Yougbare S, Chang TK, Tan SH, et al. Antimicrobial gold nanoclusters: recent developments and future perspectives. Int J Mol Sci. 2019;20(12):2924. doi:10.3390/ijms20122924

244. Zheng K, Xie J. Composition-dependent antimicrobial ability of full-spectrum $\mathrm{Au}_{\mathrm{x}} \mathrm{Ag}_{25-}$ xalloy nanoclusters. ACS Nano. 2020;14 (9):11533-11541. doi:10.1021/acsnano.0c03975

245. Zheng K, Setyawati MI, Leong DT, Xie J. Antimicrobial gold nanoclusters. ACS Nano. 2017;11(7):6904-6910. doi:10.1021/ acsnano. $7 \mathrm{~b} 02035$

246. Yang H, Cai R, Zhang Y, Chen Y, Gu B. Gold nanoclusters as an antibacterial alternative against clostridium difficile. Int J Nanomedicine. 2020;15:6401-6408. doi:10.2147/IJN.S268758

247. Gopinath K, Kumaraguru S, Bhakyaraj K, et al. Green synthesis of silver, gold and silver/gold bimetallic nanoparticles using the Gloriosa superba leaf extract and their antibacterial and antibiofilm activities. Microb Pathog. 2016;101:1-11. doi:10.1016/j. micpath.2016.10.011

248. Kwatra D, Venugopal A, Anant S. Nanoparticles in radiation therapy: a summary of various approaches to enhance radiosensitization in cancer. Transl Cancer Res. 2013;2(4):330-342. doi:10.3978/j.issn.2218-676X.2013.08.06

249. Chen Y, Yang J, Fu S, Wu J. Gold nanoparticles as radiosensitizers in cancer radiotherapy. Int $J$ Nanomedicine. 2020;15:9407-9430. doi:10.2147/IJN.S272902

250. Zhang $\mathrm{XD}$, Luo $\mathrm{Z}$, Chen $\mathrm{J}$, et al. Ultrasmall $\mathrm{Au}_{10-12(\mathrm{SG}) 10-12}$ nanomolecules for high tumor specificity and cancer radiotherapy. Adv Mater. 2014;26(26):4565-4568. doi:10.1002/ adma.201400866

251. Luo D, Wang X, Zeng S, Ramamurthy G, Burda C, Basilion JP. Targeted gold nanocluster-enhanced radiotherapy of prostate cancer. Small. 2019;15(34):1900968. doi:10.1002/smll.201900968

252. Liang G, Jin X, Zhang S, Xing D. RGD peptide-modified fluorescent gold nanoclusters as highly efficient tumor-targeted radiotherapy sensitizers. Biomaterials. 2017;144:95-104. doi:10.1016/ j.biomaterials.2017.08.017

253. Kim SR, Kim EH. Feasibility study on the use of gold nanoparticles in fractionated kilovoltage X-ray treatment of melanoma. Int $J$ Radiat Biol. 2018;94(1):8-16. doi:10.1080/ 09553002.2018.1393579

254. Shrestha B, Wang L, Zhang H, Yu Hung C, Tang L. Gold nanoparticles mediated drug-gene combinational therapy for breast cancer treatment. Int $J$ Nanomedicine. 2020;15:8109-8119. doi:10.2147/IJN.S258625

255. Haimov E, Weitman H, Polani S, Schori H, Zitoun D, Shefi O. Meso-tetrahydroxyphenylchlorin-conjugated gold nanoparticles as a tool to improve photodynamic therapy. ACS Appl Mater Interfaces. 2018;10(3):2319-2327. doi:10.1021/acsami.7b16455

256. Dai X, Zhao X, Liu Y, et al. Controlled synthesis and surface engineering of janus chitosan-gold nanoparticles for photoacoustic imaging-guided synergistic gene/photothermal therapy. Small. 2021;17(11):2006004. doi:10.1002/smll.202006004

257. García Calavia P, Chambrier I, Cook MJ, Haines AH, Field RA, Russell DA. Targeted photodynamic therapy of breast cancer cells using lactose-phthalocyanine functionalized gold nanoparticles. $J$ Colloid Interface Sci. 2018;512:249-259. doi:10.1016/j. jcis.2017.10.030 


\section{Publish your work in this journal}

The International Journal of Nanomedicine is an international, peerreviewed journal focusing on the application of nanotechnology in diagnostics, therapeutics, and drug delivery systems throughout the biomedical field. This journal is indexed on PubMed Central, MedLine, CAS, SciSearch ${ }^{\mathbb{R}}$, Current Contents ${ }^{\mathbb{B}} /$ Clinical Medicine,
Journal Citation Reports/Science Edition, EMBase, Scopus and the Elsevier Bibliographic databases. The manuscript management system is completely online and includes a very quick and fair peer-review system, which is all easy to use. Visit http://www.dovepress.com/ testimonials.php to read real quotes from published authors. 